\title{
The Atlantic's freshwater budget under climate change in the Community Earth System Model with strongly eddying oceans
}

\author{
André Jüling, Xun Zhang, Daniele Castellana, Anna S. von der Heydt, and Henk A. Dijkstra \\ Institute for Marine and Atmospheric research Utrecht (IMAU), Utrecht University, Utrecht, the Netherlands
}

Correspondence: André Jüling (a.juling@uu.nl)

Received: 23 July 2020 - Discussion started: 18 August 2020

Revised: 15 January 2021 - Accepted: 2 February 2021 - Published: 28 May 2021

\begin{abstract}
We investigate the freshwater budget of the Atlantic and Arctic oceans in coupled climate change simulations with the Community Earth System Model and compare a strongly eddying setup with $0.1^{\circ}$ ocean grid spacing to a non-eddying $1^{\circ}$ configuration typical of Coupled Model Intercomparison Project phase 6 (CMIP6) models. Details of this budget are important to understand the evolution of the Atlantic Meridional Overturning Circulation (AMOC) under climate change. We find that the slowdown of the AMOC in the year 2100 under the increasing $\mathrm{CO}_{2}$ concentrations of the Representative Concentration Pathway 8.5 (RCP8.5) scenario is almost identical between both simulations. Also, the surface freshwater fluxes are similar in their mean and trend under climate change in both simulations. While the basinscale total freshwater transport is similar between the simulations, significant local differences exist. The high-oceanresolution simulation exhibits significantly reduced ocean state biases, notably in the salt distribution, due to an improved circulation. Mesoscale eddies contribute considerably to the freshwater and salt transport, in particular at the boundaries of the subtropical and subpolar gyres. Both simulations start in the single equilibrium AMOC regime according to a commonly used AMOC stability indicator and evolve towards the multiple equilibrium regime under climate change, but only the high-resolution simulation enters it due to the reduced biases in the freshwater budget.
\end{abstract}

\section{Introduction}

One of the important tipping elements in the climate system (Lenton et al., 2008) is the Atlantic Meridional Overturning Circulation (AMOC). This component of the ocean circula- tion carries about $1.5 \mathrm{PW}$ of heat northwards at $26.5^{\circ} \mathrm{N}$ in the Atlantic (Johns et al., 2011), and hence its strength and spatial expression significantly affect local surface temperature and precipitation (Palter, 2015). The potential tipping character of the AMOC is expressed through large and abrupt changes in AMOC strength (Srokosz et al., 2012; Weijer et al., 2019), for which evidence exists in the palaeo record (Lynch-Stieglitz, 2017). In models of the AMOC, such transitions can occur due to the existence of multiple equilibria, where several AMOC states can coexist under the same forcing conditions. Such multiple equilibria of the AMOC have been found in a hierarchy of ocean-climate models (Stommel, 1961; Rahmstorf et al., 2005; Hawkins et al., 2011; Toom et al., 2012; Mecking et al., 2016). They occur due to the presence of positive feedbacks, the most prominent one being the salt advection feedback (Peltier and Vettoretti, 2014). Subtle changes to the freshwater budget can modify the AMOC response to perturbations which is why the correct simulation of the oceanic freshwater budget in the Arctic and Atlantic is important (Behrens et al., 2013).

The Atlantic is a net evaporative basin resulting in the saltiest subtropical surface waters of all the major oceans. At the Atlantic's southern boundary, which we take to coincide with the southern tip of Africa at $34^{\circ} \mathrm{S}$, relatively salty surface waters together with fresh Antarctic Intermediate Water (AAIW) are imported in the upper $1000 \mathrm{~m}$. This northward transport amounts to approximately $17 \mathrm{~Sv}$ at $26.5^{\circ} \mathrm{N}$ (Moat et al., 2020; Smeed et al., 2018; Frajka-Williams et al., 2019). At high northern latitudes, the surface waters are transformed into North Atlantic Deep Water (NADW) which returns southwards and is exported at $34^{\circ} \mathrm{S}$. A lower, weaker overturning cell exists in which cold Antarctic Bottom Water enters the South Atlantic at the bottom and returns just 
above with the NADW. Salt also enters the South Atlantic from the southwest Indian Ocean via Agulhas leakage in the form of eddies shed off the Agulhas retroflection (McDonagh et al., 1999). From the north, approximately $0.8 \mathrm{~Sv}$ of relatively fresh Pacific water enters the Arctic Ocean via the Bering Strait where it further freshens primarily due to river discharge from the large Arctic catchment area (Woodgate and Aagaard, 2005). Together with freshwater in the form of sea ice, relatively fresh seawater enters the Atlantic from the north. In the Strait of Gibraltar, relatively fresh surface waters flow into the strongly evaporative Mediterranean Sea and saltier waters return into the Atlantic at depth. The meridional asymmetry of the precipitation pattern of the Intertropical Convergence Zone (ITCZ) results in salinity differences between the North and South Atlantic. The wind-driven subtropical and subpolar gyres recirculate water primarily horizontally and advect any zonal salinity gradient also in the meridional direction.

As atmospheric temperatures rise under increasing greenhouse gas concentrations, the hydrological cycle generally strengthens, making dry regions drier and wet regions wetter, amplifying sea surface salinity patterns (Held and Soden, 2006; Skliris et al., 2020). The AMOC is projected to weaken under climate change due to buoyancy flux changes as heat flux and net precipitation patterns change (Stocker et al., 2013). The heat flux changes are the dominant driver of AMOC strength reduction, and there is evidence that this slowdown is already underway (Gregory et al., 2005; Caesar et al., 2018). In order to judge how fast the AMOC can change and whether it could collapse abruptly, one needs to assess the AMOC stability and in particular the strength of the positive feedbacks. In Coupled Model Intercomparison Project phase 5 (CMIP5) models, no transition to a different statistical equilibrium state is found up to the year 2100 under any of the climate change scenarios (Cheng et al., 2013), and it remains unclear whether the AMOC is already in or will shift into a multiple equilibrium regime, which would allow such transitions (Gent, 2018).

Many studies have linked the freshwater budget, through the salt advection feedback, to the response of the AMOC under surface freshwater perturbations (Rahmstorf, 1996; de Vries, 2005; Dijkstra, 2007; Mecking et al., 2017; Liu et al., 2017). The existence of a multiple equilibrium regime is connected to the sign of the divergence of the advective AMOC induced Atlantic freshwater transport $\Sigma$ (or $\Delta M_{\mathrm{ov}}$ in Liu et al., 2017) which exactly marks the separation of the unique and multiple equilibrium regimes when atmospheric feedbacks are negligible (Dijkstra, 2007). As the northern boundary freshwater transport is minor, this divergence is often approximated by its southern boundary component only, referred to as $M_{\mathrm{ov}}$ (de Vries, 2005), $F_{\mathrm{ov}}$ (Hawkins et al., 2011), or $F_{\text {ovS }}$ (Weijer et al., 2019). We will use $F_{\text {ovS }}$ here as we use $F$ to denote freshwater fluxes in general and $F_{\mathrm{ov}}$ for the latitudinally dependent overturning component in particular. We define freshwater relative to a salinity of $S_{0}=35$ and detail the computations of the different transport components in Appendix B. Positive $F_{\mathrm{ovS}}$ values indicate that the AMOC imports freshwater which constitutes a negative feedback as a positive AMOC strength perturbation would be damped by an enhanced freshwater import into the North Atlantic, suppressing deep water formation. A negative $F_{\text {ovS }}$ value, on the other hand, would induce an amplification of an AMOC perturbation (Huisman et al., 2010). Observational estimates of $F_{\text {ovS }}$ are negative suggesting multiple AMOC equilibria in the present-day climate (Weijer et al., 2019). The models of CMIP3 and CMIP5 tend to have positive $F_{\text {ovS }}$ values due to a salinity bias at $34^{\circ} \mathrm{S}$, where the upper water masses are too fresh and the deep southward return flow is too salty (Drijfhout et al., 2011; Weaver et al., 2012; Liu et al., 2014; Mecking et al., 2017). Once this bias is accounted for, $F_{\mathrm{ovS}}$ values for most models lie within the range of observations (Mecking et al., 2017). Under increasing radiative forcing, CMIP3 models exhibit a negative $F_{\text {ovS }}$ trend (Drijfhout et al., 2011), but no consistent sign in this trend is found in CMIP5 models (Weaver et al., 2012).

Refining the grid spacing from $1^{\circ}$ typical of CMIP5 and CMIP6 ocean model components to $0.1^{\circ}$ resolves the internal Rossby radius of deformation over large parts of the ocean (Hallberg, 2013). This enables the development of eddies, filaments, and fronts through mixed barotropic/baroclinic instabilities and the simulation of other mesoscale ocean features such as currents at the western boundary and through narrow straits. We use the terminology "strongly eddying" for ocean grids with $0.1^{\circ}$ horizontal grid spacing as these are neither just eddy-permitting (typically $0.25^{\circ}$ ) nor fully mesoscale turbulence resolving (Moreton et al., 2020). These high-resolution ocean models constitute the only consistent method to estimate eddy contributions to ocean variability and the mean climate state and generally result in significantly reduced ocean biases (Kirtman et al., 2012; Small et al., 2014). The eddy freshwater transport is comparable in magnitude to the mean transport at the poleward and equatorward boundaries of the subtropical gyres (Treguier et al., 2012, 2014). Some of this transport will be captured by eddy parameterizations in low-resolution simulation, but other effects, such as the advection of salt by Agulhas rings, cannot be captured adequately.

Relatively few studies have investigated the AMOC behavior in strongly eddying ocean models (Weijer et al., 2012; den Toom et al., 2014; Brunnabend and Dijkstra, 2017; Hirschi et al., 2020). The improved simulation of overflows over sills in high-resolution models significantly reduces deep water density biases which leads to improved simulation of deep convection. The pathway of the North Atlantic Current and the formation sites of North Atlantic Deep Water are more realistic at high resolution (Hirschi et al., 2020). A comparison of the AMOC response between 10 Geophysical Fluid Dynamics Laboratory (GFDL) models under a $1 \% \mathrm{yr}^{-1} \mathrm{CO}_{2}$ increase scenario showed that in coarse-resolution models, the AMOC declines between $16 \%$ 
and $45 \%$, and the eddy-permitting and strongly eddying configurations are at the lower end of these percentages with $13 \%$ and $16 \%$, respectively (Winton et al., 2014). The POP ocean model showed qualitatively similar AMOC responses to surface freshwater perturbations between strongly eddying $\left(0.1^{\circ}\right)$ and non-eddying $\left(1^{\circ}\right)$ model configurations (Weijer et al., 2012; den Toom et al., 2014; Brunnabend and Dijkstra, 2017) but with a dependence on the location of the perturbation. However, whether ocean model resolution affects the AMOC response to forcing systematically remains an open question (Gent, 2018), although there is evidence from eddy-permitting models that the AMOC mean state, in particular the sites of deep water formation, controls the response (Jackson et al., 2020). A suite of high-resolution ocean-only hindcasts with the Nucleus for European Modelling of the Ocean (NEMO) model at $1 / 12^{\circ}$ show that the stability indicator $F_{\mathrm{ovS}}$ is negative (Deshayes et al., 2013) in contrast to coarse-resolution coupled models (Mecking et al., 2017). The NEMO model thus shows a reduced bias in $F_{\text {ovs }}$, but it remains unclear how much of the bias reduction is due to the use of restoring boundary conditions within the oceanonly setup and how much is due to an improved mean state of the ocean circulation.

As coarse-resolution models exhibit biases in their mean state and lack mesoscale processes, the simulated sensitivity to forcing may be inadequate and the strength of the salt advection feedback may be affected. We investigate the effect of improving the ocean model resolution on the Atlantic freshwater budget and its sensitivity by analyzing presentday control and high- $\mathrm{CO}_{2}$ concentration pathway simulations in two configurations of the Community Earth System Model: one with an ocean model grid spacing of $0.1^{\circ}$ and the other with $1^{\circ}$. The following section (Sect. 2) describes these model simulations and provides a model-observation comparison of the control simulations. Section 3 presents the results, including changes to the AMOC, the Atlantic freshwater and salt budgets, and the effects on AMOC stability, under the climate change scenario. The results are summarized and discussed in Sect. 4.

\section{Model simulations and model-observation comparison}

\subsection{CESM simulations}

We analyze four simulations with the Community Earth System Model version 1 (CESM1; Hurrell et al., 2013), carried out at the Academic Computing Center in Amsterdam (SURFsara); see, e.g., van Westen and Dijkstra (2017). The CESM components are CAM5 (Community Atmosphere Model version 5), POP2 (Parallel Ocean Program 2), CICE (Los Alamos Sea Ice Model), and CLM (Community Land Model), which are coupled by the CESM1 coupler. The ocean model formulation is volume conserving, and sur- face freshwater fluxes are thus modeled as virtual salt fluxes. The high-resolution ("HR") simulation was performed with a $0.1^{\circ}$ ocean horizontal grid spacing on a tripolar grid, while the low-resolution ("LR") simulation was conducted with $1^{\circ}$ ocean horizontal grid spacing with a displaced dipole grid. Tracer diffusing subgrid-scale processes are parameterized by the Gent-McWilliams scheme (Gent and McWilliams, 1990) in the $1^{\circ}$ simulation and by biharmonic diffusion in the $0.1^{\circ}$ case, which is strongly eddying.

Both control simulations use constant year-2000 atmospheric greenhouse gas concentrations forcing (notably $\left.\left[\mathrm{CO}_{2}\right]=367 \mathrm{ppm},\left[\mathrm{CH}_{4}\right]=1760 \mathrm{ppb}\right)$. The HR-CESM simulation continues from a National Center for Atmospheric Research (NCAR) simulation of several decades which itself was initialized from a motionless ocean with a present-day estimate of the ocean's temperature and salinity distribution. The LR-CESM simulation was similarly continued from an NCAR-provided initial state. The climate change simulations are following the $\mathrm{CO}_{2}$ concentration of the highest Representative Concentration Pathway (RCP8.5) of CMIP5 used in the Fifth Assessment Report of the Intergovernmental Panel on Climate Change (Stocker et al., 2013) but do not include other greenhouse gas increases or land use changes. We name the present-day control simulation CTRL and the climate change simulation RCP. In 2100, the radiative forcing of $\mathrm{CO}_{2}$ alone is $6.9 \mathrm{~W} \mathrm{~m}^{-2}$, or $80 \%$ of the $8.5 \mathrm{~W} \mathrm{~m}^{-2}$ of the RCP8.5 scenario (van Vuuren et al., 2011). Not prescribing land use changes has no effect on the global mean surface temperature in the RCP8.5 scenario (Davies-Barnard et al., 2014). Compared to the mean warming in 2100 of the two RCP8.5 CESM1/CAM5 simulations submitted to CMIP5 at $4.4^{\circ} \mathrm{C}$ (Meehl et al., 2013; time series available at https://climexp.knmi.nl/CMIP5/Tglobal/, last access: 30 April 2021), our LR-CESM RCP simulation warmed only $2.9^{\circ} \mathrm{C}$, or $66 \%$ of the RCP8.5 value. The reduced warming until 2100 is both because of the aforementioned reduced radiative forcing but also because our simulation started from a nearly equilibrated, and hence relatively warm, year-2000 control simulation. The main characteristics of the model simulations are summarized in Table 1.

There are additional differences between the model configurations apart from the horizontal ocean model resolution. The $0.1^{\circ}$ POP2 model grid has 42 levels to $6000 \mathrm{~m}$, while the LR-POP2 grid has 60 levels to $5500 \mathrm{~m}$. In contrast to the HR-CESM ocean grid with its partial bottom cells and explicitly resolved overflows, the LR-CESM grid is defined with complete bottom cells and uses overflow parameterizations, e.g., between the Nordic Seas and the Atlantic (Smith et al., 2010). In the $0.1^{\circ}$ POP 2 model, the explicitly modeled Nordic Seas overflows compare favorably to observations (Ypma et al., 2019). The Mediterranean outflow is not parameterized in the $1^{\circ}$ POP2 grid but is modeled with a widened Strait of Gibraltar. Ultimately, the effect of the different vertical resolutions is hard to disentangle as the horizontal mixing is represented very differently. Further, the 
Table 1. Overview of the CESM simulations used, their ocean and atmosphere grid, and the model version, as well as the year at which the RCP simulations are branched off the CTRL simulations.

\begin{tabular}{lllllll}
\hline Setup & \multicolumn{1}{c}{ Ocean grid } & & Atmosphere grid & CESM version & Start of RCP [year] \\
\hline HR-CESM & $0.1^{\circ}$ tripole, 42 levels to $6000 \mathrm{~m}$ & tx0.1v2 & $0.47^{\circ} \times 0.63^{\circ}$ & $f 05$ & 1.0 .4 & 200 \\
LR-CESM & $1^{\circ}$ dipole, 60 levels to $5500 \mathrm{~m}$ & gx1v6 & $0.9^{\circ} \times 1.25^{\circ}$ & $\mathrm{f09}$ & 1.1 .2 & 500 \\
\hline
\end{tabular}

CESM versions and atmosphere resolution differ between the HR-CESM (version 1.0.4) and the LR-CESM simulations (version 1.1.2). The newer version employs a different dynamical core in the atmosphere model (CAM5.2 versus CAM5.0), and some parameterization schemes are updated. In contrast to the improvement in ocean model resolution, however, halving the atmospheric grid spacing from 1 to $0.5^{\circ}$ is not resolving new essential physical processes. Therefore, no significant changes are expected between the $0.5^{\circ}$ CAM5.0 HR-CESM and $1^{\circ}$ CAM5.2 LR-CESM simulations' atmospheres due their resolved physics apart from coupling to different ocean boundary conditions.

\subsection{Model-observation comparison}

To assess the performance of the HR- and LR-CESM CTRL simulations, we use several observational datasets which are relevant for the freshwater budget and compare 30-year means of the CTRL simulations following the RCP branchoff point (years 200-229 and 500-529; see Table 1). In many aspects the HR-CESM CTRL simulation performs better than the LR-CESM CTRL simulation when compared to the present-day climate. Global maps of the quantities presented here for the Atlantic-Arctic are included in Appendix A. When linear fits are presented, such as in Fig. 1d and e, significance of the fit is tested with a Wald test against a zeroslope null hypothesis.

We define regions in the Atlantic that approximately correspond to the subtropical gyres (STGs; sometimes specified as South or North Atlantic: SA-STG and NA-STG), the subpolar gyre (SPG), the ITCZ, and the Arctic. Green lines in Fig. $1 \mathrm{~b}$ and $\mathrm{c}$ show bounding latitudes which are at the southern end of the Atlantic basin around $34^{\circ} \mathrm{S}, 10^{\circ} \mathrm{S}$, and $10^{\circ} \mathrm{N}$ generously bounding the ITCZ, $45^{\circ} \mathrm{N}$ as the approximate boundary of the subtropical and subpolar gyres, and $60^{\circ} \mathrm{N}$ as the boundary between the Atlantic and the Arctic. The Arctic Ocean includes Hudson Bay and is bounded on the Pacific side by the Bering Strait at $68^{\circ} \mathrm{N}$. We perform the calculations on the original model 0.1 and $1^{\circ}$ grids which become distorted relative to a regular latitude-longitude grid at high northern latitudes (see $60^{\circ} \mathrm{N}$ line in Fig. 1).

\subsubsection{Sea surface temperature}

The sea surface temperature (SST) is important for the freshwater budget as it strongly controls evaporation. Figure 1 shows the Hadley Centre Sea Ice and Sea Surface Tem- perature dataset (HadISST) 1990-2019 climatology (Rayner et al., 2003), the bias of the CTRL simulations with respect to that climatology, and the linear SST trends of the RCP simulations. The HR-CESM (LR-CESM) simulation global mean SST is about $0.51(0.86) \mathrm{K}$ too warm with a RMSE of 0.99(1.39) K compared to the HadISST dataset. Some warm bias is to be expected as the simulations are subjected to constant year-2000 radiative forcing and not the transiently increasing historical forcing. In the HR-CESM Atlantic, the sea surface is slightly too cold equatorward of $30^{\circ}$ and too warm poleward of these latitudes with the exception of the South Atlantic near the African coast. The LR-CESM SST biases are stronger with warm biases in the South Atlantic, along the North American east coast due to the Gulf Stream separating too far north, and north of $50^{\circ} \mathrm{N}$. The LR-CESM NA-STG and the southern edge of the NA-SPG are too cold resulting in asymmetric bias around the Equator. Both simulations SSTs are too high in the NADW formation areas which results in warm biases in this water mass. The RCP SST trends are positive everywhere with a marked Arctic amplification. The exception is the NA-SPG with negative SST trends, an expected response associated with an AMOC decline under radiative forcing (Drijfhout et al., 2012).

\subsubsection{Surface freshwater fluxes}

We compare surface freshwater fluxes to the ERA-Interim precipitation minus evaporation, $P-E$, 1989-2010 climatology (Dee et al., 2011; Trenberth et al., 2011). Figure 2 shows maps of the observed mean $P-E$ and the bias of the two simulations, and the zonally integrated $P-E$ fluxes. There is net evaporation in the STGs and net precipitation in the ITCZ just north of the Equator (Fig. 2a) and the midlatitudes to high latitudes. Both simulations exhibit the same positive global precipitation biases of $0.23 \pm 1.01 \mathrm{~mm} \mathrm{~d}^{-1}$ (mean \pm RMSE; see Appendix A). The $P-E$ bias is negative almost everywhere in the HR-CESM Atlantic (Fig. 2b) and over large parts of the LR-CESM Atlantic (Fig. 2c). Both simulations show biases around the ITCZ, most noticeably with reduced precipitation near the South American coast north of the Equator. The HR-CESM ITCZ appears slightly rotated with a wider precipitation belt in the central equatorial Atlantic and reduced precipitation in the northwest and southeast. The LR-CESM ITCZ is shifted south because the SST bias (see Fig. 1c) is meridionally asymmetric around the Equator. As the surface waters diverge at the Equator this contributes to the saline (fresh) surface bias of the North 

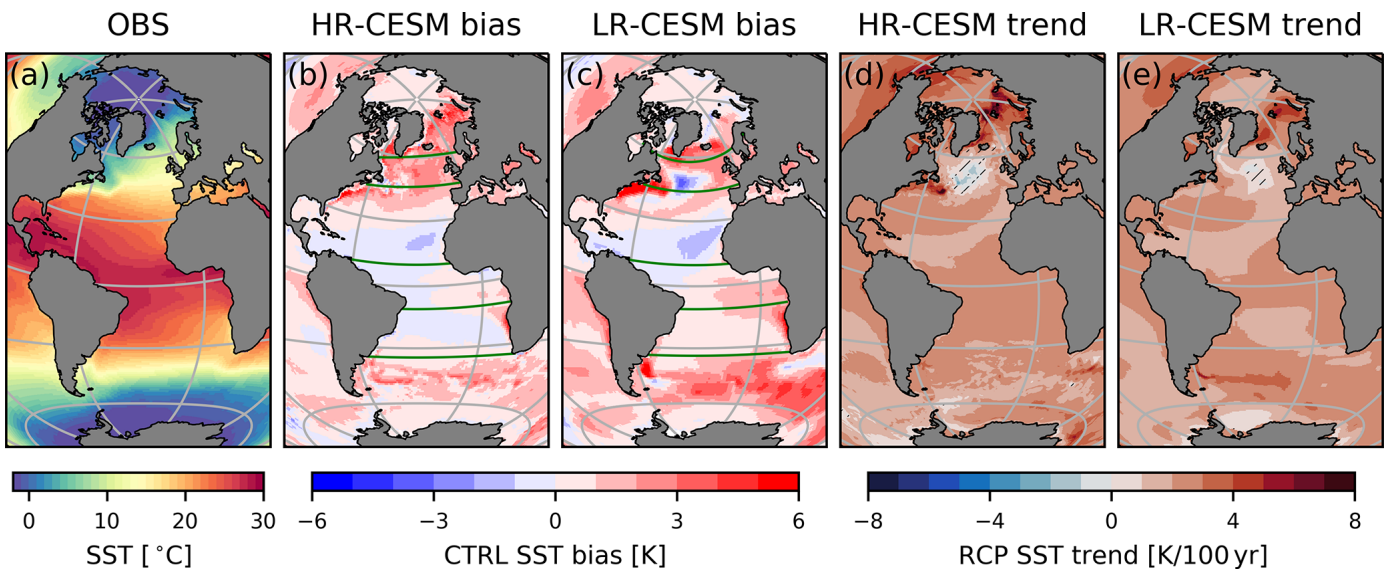

Figure 1. The sea surface temperature (SST) from the HadISST 1990-2019 observations (a), the SST bias of the HR-CESM (b) and LRCESM (c) CTRL simulations, and the linear trends of the HR-CESM (d) and LR-CESM (e) RCP climate change scenarios. Hatched areas in the trend maps are not significant at the $5 \%$ level. The Lambert azimuthal projection of these and subsequent maps is an equal-area projection, and gray parallels (meridians) are drawn every $30^{\circ}\left(60^{\circ}\right)$. The green lines $(\mathbf{b}, \mathbf{c})$ show transects in the tripolar $0.1^{\circ}$ and dipolar $1^{\circ}$ POP 2 model grid at $34,10^{\circ} \mathrm{S}, 10^{\circ} \mathrm{N}$, and approximately 45 and $60^{\circ} \mathrm{N}$. This northernmost meridional boundary differs from the $60^{\circ} \mathrm{N}$ parallel because of the curvilinear grids and is chosen to lie south of the Hudson Strait.
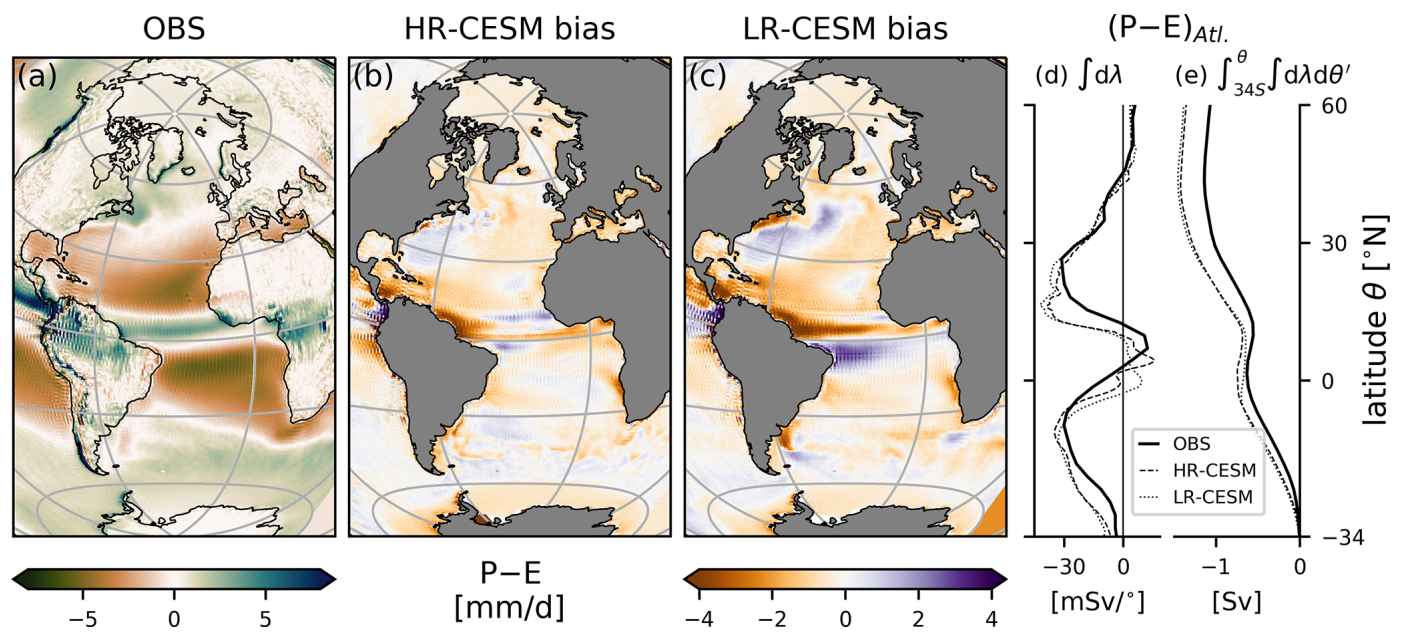

Figure 2. Precipitation minus evaporation: the observed ERA-Interim 1980-2010 climatology (a) and the biases of the HR-CESM (b) and LR-CESM (c) CTRL simulations. The zonally integrated $P-E$ fluxes per degree latitude (d) and the implied freshwater transport due to the $P-E$ fluxes (e) assuming zero transport at $34^{\circ} \mathrm{S}$ and constant salt content in the oceans. Note that this does not include runoff freshwater contributions.

(South) Atlantic. Around the Gulf Stream too much water evaporates, but this is stronger and extends further north in the LR-CESM simulation, reflecting SST biases there (see Fig. 1c). Both the flux per degree latitude and the meridionally integrated flux referenced to zero transport at $34^{\circ} \mathrm{S}$ shown in Fig. 2d and e reveal comparable biases in the zonal integrals with minor differences in the ITCZ.

\subsubsection{Salinity distribution}

The heterogeneous salinity distribution in the ocean is the result of surface exchanges of freshwater and redistribution by the circulation. We use the EN4 global salinity obser- vations averaged over 1990-2019 which are provided on a $1^{\circ} \times 1^{\circ}$ grid (Good et al., 2013). To compare to the model data, we first interpolated the EN4 data bilinearly horizontally and then linearly to the model depth coordinates for both HR- and LR-CESM ocean grids. Figure 3 shows the observed salinity distribution and the simulation biases of the upper $100 \mathrm{~m}$, as an Atlantic zonal mean, and along a zonal transect at $34^{\circ} \mathrm{S}$. Both HR-CESM (Fig. 3b) and LR-CESM (Fig. 3c) show a similar bias pattern with a positive surface bias in the North Atlantic and parts of the Arctic, and a negative bias in the South Atlantic and the rest of the global ocean (Appendix Fig. A3). The Atlantic zonally averaged profile 

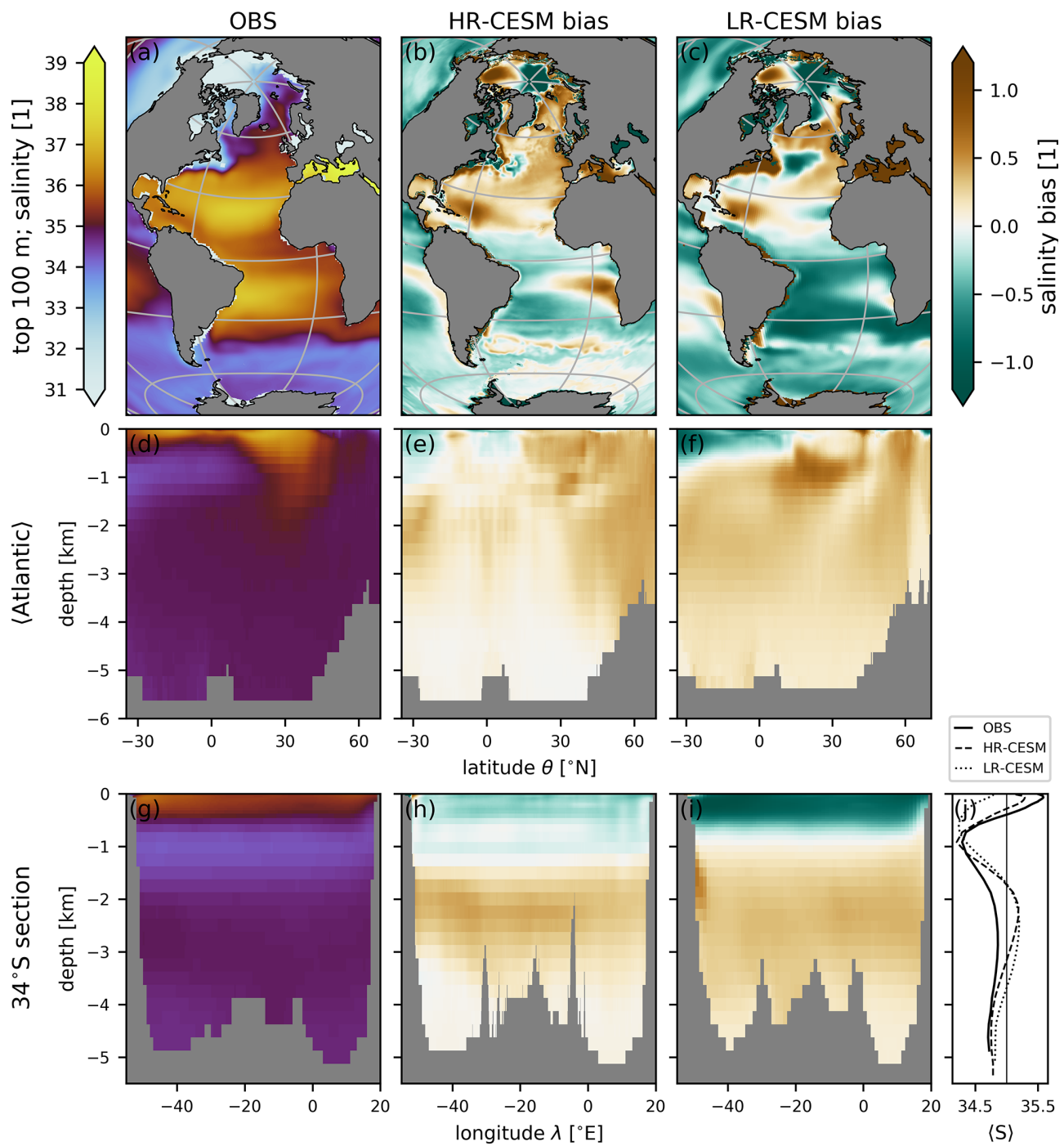

Figure 3. The salinity distribution in the EN4 observations (a, d, g) and the bias of the HR-CESM (b, e, h) and LR-CESM (c, f, i) CTRL simulations for the top $100 \mathrm{~m}(\mathbf{a}, \mathbf{b}, \mathbf{c})$, zonally averaged in the Atlantic (d, e, f), and at the $34^{\circ} \mathrm{S}$ transect (g, h, i). Panel (j) shows zonally averaged salinity profiles for observations (thick solid line) and the HR-CESM (dashed) and LR-CESM (dotted) simulations together with the reference salinity $S_{0}=35$ (thin solid). Note that salinity as a mass fraction is dimensionless.

(Fig. 3d) shows the largest salinity values in the evaporative subtropical gyres with less saline waters of the NADW with $S=34.9-35.0$ at high northern latitudes and between 1500 and $4000 \mathrm{~m}$, while relatively fresh AAIW is visible around $1000 \mathrm{~m}$ depth up to $10^{\circ} \mathrm{N}$. The AAIW is visible in the $34^{\circ} \mathrm{S}$ transect (Fig. 3g) and the section average (Fig. 3j). The bias in HR-CESM is significantly reduced compared the LRCESM simulation in all three planes. In particular, the LRCESM simulation bias around $1000 \mathrm{~m}$ depth and $15-30^{\circ} \mathrm{N}$ (Fig. 3f) can be attributed to the absence of eddies (Treguier et al., 2014).

\subsubsection{Circulation and gateway transport}

In Fig. 4a, b, and c, we compare the standard deviation of the observed sea surface height (SSH; Zlotnicki et al., 2019) and the modeled dynamic sea level to illustrate the fidelity of the HR-CESM simulation. The SSH observations are provided as $5 \mathrm{~d}$ means on a $1 / 6^{\circ}$ grid, and some polar data are missing. For Fig. 4a, we use the year 2018 to calculate the standard deviation from the $5 \mathrm{~d}$ means. In Fig. $4 \mathrm{~b}$ and c, we calculate the standard deviation for the branch-off year of the CTRL simulations based on the $\mathrm{SSH}^{2}$ and SSH output variables. This means that the modeled dynamic sea level standard deviation uses the model time step as the sampling frequency, in effect capturing more variability than the $5 \mathrm{~d}$ sampling of the observations. The observations and model are thus not directly 

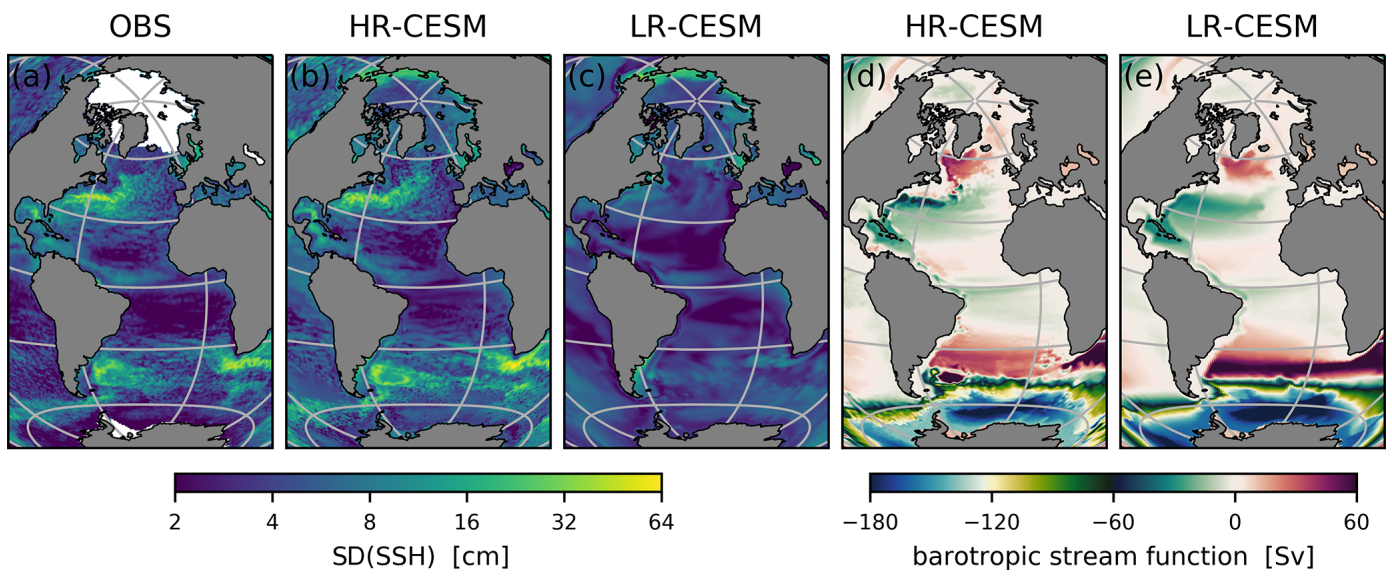

Figure 4. (a) The standard deviation of the observed sea surface height anomalies on a $1 / 6^{\circ}$ grid (Zlotnicki et al., 2019). Missing data are white. (c, d) The dynamic sea level standard deviation of the HR- and LR-CESM CTRL simulations. (d, e) The mean barotropic streamfunction $\Psi$ of the HR- and LR-CESM CTRL simulations relative to the African Atlantic coast.

comparable in all details, but the LR-CESM clearly lacks variability compared to the observations and HR-CESM, in particular in regions of the Gulf Stream and its extension, the Agulhas retroflection, the Argentine Basin, and the Antarctic Circumpolar Current.

To explain several of the HR- and LR-CESM salinity distribution biases, we plot the barotropic streamfunction for both CTRL cases in Fig. 4d and e. We approximate the barotropic streamfunction $\Psi$ as $\Psi(\lambda, \theta)=$ $\int_{\theta^{\prime}=\theta_{S}}^{\theta} \int_{z=D}^{0} u\left(\lambda, \theta^{\prime}, z\right) \mathrm{d} z \mathrm{~d} \theta^{\prime}-\Psi_{0}$. Here, the vertical integral of the zonal velocity $u$ is taken over the full depth from $z=D$ to the surface $z=0$, the meridional integral is taken from the southern boundary at Antarctica $\left(\theta=\theta_{S}\right)$ and is subsequently set to 0 at the African Atlantic coast by removing a constant $\Psi_{0}$. In LR-CESM, the barotropic streamfunction is diagnosed and part of the model output and this field agrees well with our approximation. For consistency, we present our approximation for both HR- and LR-CESM.

While the broad-scale wind-driven subtropical and subpolar gyre circulation are present in both simulations, HRCESM features stronger boundary currents, standing eddies, a more realistic Agulhas retroflection pathway and Gulf Stream separation point, and a stronger subpolar gyre which extends much further south along the North American coast. In LR-CESM, the inflow of Indian Ocean waters is unrealistically strong and together with the strong upper $100 \mathrm{~m}$ fresh bias of the Indian Ocean (Appendix Fig. A3) contributes to the negative salinity bias of the South Atlantic (Fig. 3). In the RCP scenario, the Gulf Stream in HR-CESM shifts northward, which is expected under climate change (Yang et al., 2020). In LR-CESM, the subpolar gyre weakens broadly, while in HR-CESM only the boundary currents weaken (not shown).

The freshwater fraction $W$, which we call freshwater for brevity, is defined relative to a reference salinity $S_{0}$ as $W=$ $\left(S-S_{0}\right) / S_{0}$, where $S$ is the (dimensionless) salinity of a given ocean water parcel. We choose $S_{0}=35$, as this is the salinity of the modeled North Atlantic Deep Water and close to the average salinity at $34^{\circ} \mathrm{S}$ (see Figs. 3d, g, and j). In principle, the freshwater framework has disadvantages, as the choice of the reference salinity $S_{0}$ is arbitrary and the amount of freshwater depends non-linearly on it (Schauer and Losch, 2019). However, the relevant terms relate to recirculating and eddy flows which are independent of $S_{0}$ (see Appendix B), and the AMOC stability criterion $F_{\mathrm{ovS}}$ is framed in terms of freshwater. Only the barotropic transport depends on $S_{0}$, and this component is negligible for the Atlantic freshwater transport although it contributes significantly to the total salt transport.

For the Atlantic-Arctic basin the only oceanic exchanges of freshwater and salt north of $34^{\circ} \mathrm{S}$ occurs at Bering Strait with the Pacific Ocean and through the Strait of Gibraltar with the Mediterranean Sea. Table 2 summarizes the observed and simulated transport of seawater, salt, and freshwater. The Mediterranean is a net evaporative basin with a small net volume inflow at the Strait of Gibraltar but an overturning that is about 20 times stronger, importing waters with a salinity of 36.2 and exporting Mediterranean Overflow Water at a salinity of 38.4 at a depth of $1000 \mathrm{~m}$ (Sánchez-Román et al., 2009). In reality, there is no source of salt in the Mediterranean, but as the model formulation is volume conserving, there is no net flow through the Strait of Gibraltar and the net evaporation in the model Mediterranean represents a virtual salt source. An overturning of $0.8 \mathrm{~Sv}$ with the aforementioned salinity differences would result in a salt transport of $1.8 \mathrm{kt} \mathrm{s}^{-1}$ into the Atlantic. The model salt transport of both simulations is somewhat smaller at $1.2 \pm 0.1 \mathrm{kt} \mathrm{s}^{-1}$, which is equivalent to a freshwater transport of $32 \pm 2 \mathrm{mSv}$. Through the shallow Bering Strait, relatively fresh water with mean salinity of $32.5 \pm 0.3$ flows northward into the Arctic Ocean because of dynamic sea level differences between the Arctic and North Pacific (Woodgate and Aagaard, 2005). 
Table 2. Transport into the Atlantic of seawater, salt, and freshwater through the Bering Strait (Woodgate and Aagaard, 2005), the Strait of Gibraltar (Sánchez-Román et al., 2009), and across $24^{\circ} \mathrm{S}$ (Bryden et al., 2011). The barotropic seawater volume transport $F_{\text {bt }}^{V}$ is given for all three transects and the overturning volume transport $F_{\mathrm{ov}}^{V}$ is given for the Strait of Gibraltar and at $24^{\circ} \mathrm{S}$. The mean salt transport $F_{\text {mean }}^{S}$ across a section is defined as the integrated product of monthly salinity and velocity fields (the unit $\left[\mathrm{kt} \mathrm{s}^{-1}\right]$ is equivalent to the also commonly used [Sv psu]). The mean freshwater transport $F_{\text {mean }}$ is defined similarly with the reference salinity $S_{0}=35$. The freshwater transport overturning component $F_{\mathrm{OV}}$ is given only at $24^{\circ} \mathrm{S}$. The \pm denotes uncertainties in the observations and interannual standard deviations in the simulations. The two values for the observations at $24^{\circ} \mathrm{S}$ are estimates from two separate cruises.

\begin{tabular}{lllrrr}
\hline Transect & Term & Units & OBS & HR-CESM & LR-CESM \\
\hline \multirow{2}{*}{ Bering } & $F_{\text {bt }}^{V}$ & {$[\mathrm{~Sv}]$} & $0.8 \pm 0.1$ & $1.6 \pm 0.1$ & $1.0 \pm 0.1$ \\
& $F_{\text {mean }}^{S}$ & {$\left[\mathrm{kt} \mathrm{s}^{-1}\right]$} & $26 \pm 3$ & $51 \pm 4$ & $32 \pm 1$ \\
& $F_{\text {mean }}$ & {$[\mathrm{mSv}]$} & $140 \pm 20$ & $100 \pm 30$ & $100 \pm 30$ \\
\hline Gibraltar & $F_{\text {bt }}^{V}$ & {$[\mathrm{mSv}]$} & $-38 \pm 7$ & $0 \pm 4$ & $0 \pm 3$ \\
& $F_{\text {ov }}^{V}$ & {$\left[\mathrm{mSv}^{-1}\right.$} & 800 & $430 \pm 31$ & $300 \pm 25$ \\
& $F_{\text {mean }}^{S}$ & {$\left[\mathrm{kt} \mathrm{s}^{-1}\right]$} & 0 & $1.1 \pm 0.2$ & $1.1 \pm 0.1$ \\
& $F_{\text {mean }}$ & {$[\mathrm{mSv}]$} & -50 & $-32 \pm 2$ & $-32 \pm 2$ \\
\hline \multirow{2}{*}{$24^{\circ} \mathrm{S}$} & $F_{\text {bt }}^{V}$ & {$[\mathrm{~Sv}]$} & $-0.755,-0.630$ & $-1.6 \pm 0.1$ & $-1.0 \pm 0.1$ \\
& $F_{\text {ov }}^{V}$ & {$[\mathrm{~Sv}]$} & 21.5 & $17.0 \pm 0.8$ & $16.4 \pm 0.7$ \\
& $F_{\text {mean }}^{S}$ & {$\left[\mathrm{kt} \mathrm{s}{ }^{-1}\right]$} & +0.3 & $-67 \pm 5$ & $-47 \pm 3$ \\
& $F_{\text {mean }}$ & {$[\mathrm{mSv}]$} & $-2.9,-2.4$ & $290 \pm 13$ & $340 \pm 14$ \\
& $F_{\text {ov }}$ & {$[\mathrm{mSv}]$} & $-130,-90$ & $160 \pm 10$ & $270 \pm 10$ \\
\hline
\end{tabular}

Table 2 also lists the transport terms at $24^{\circ} \mathrm{S}$ as Bryden et al. (2011) provide $F_{\mathrm{ov}}$ estimates from two cruises at this latitude. The simulated barotropic volume transport at $24^{\circ} \mathrm{S}$ equals that through the Bering Strait, because the model is volume conserving. The corresponding virtual salt flux formulation is also the reason why the simulated mean salt transport is very negative, while observations show a small northward salt transport. Both simulations' overturning circulations are weaker than observed, and the freshwater transport due to the overturning is of opposite sign compared to the observations.

\section{Results}

\subsection{AMOC}

Figure $5 \mathrm{a}$ and $\mathrm{b}$ show the AMOC streamfunction $\psi(\theta, z)$ of the CTRL mean state (shading) together with the RCP trends (contours) in both HR- and LR-CESM. The maximum of $\psi$ is located just below $1000 \mathrm{~m}$ depth for both simulations around $35^{\circ} \mathrm{N}$, but the LR-CESM simulation upper cell stretches further north consistent with its STG that extends too far north (see Fig. 4). The Antarctic Bottom Water cell is stronger and extends further north in HR-CESM. Both simulations experience a similar weakening and shoaling trend of the upper cell and a slight strengthening of the lower cell. The HR-CESM latitudinal gradient in the weakening trend around the maxima at $2000 \mathrm{~m}$ is weaker so that the HRCESM AMOC weakening is stronger at $34^{\circ} \mathrm{S}$ but weaker in the Northern Hemisphere compared to the LR-CESM simulation.

The evolution of the AMOC strength is measured at the latitude of the RAPID mooring array, $26.5^{\circ} \mathrm{N}$, and the depth of maximum overturning, $1000 \mathrm{~m}$ (white crosses in Fig. 5a and b). In contrast to the RAPID array data, the streamfunction in Fig. 5c contains negligible contributions from the Gulf of Mexico at $26.5^{\circ} \mathrm{N}$. Figure $5 \mathrm{~d}$ and e show time series of the AMOC strength, including 100 years prior to the RCP branch-off point to show the statistically equilibrated nature of the time series. Both simulations' CTRL mean AMOC strength compare favorably to the observations with approximately $18 \mathrm{~Sv}$ (Frajka-Williams et al., 2019), and they respond with a similar linear weakening trend of $4.7 \mathrm{~Sv}$ per century and 5.2 Sv per century to the RCP forcing, respectively. The monthly variability (thin line) of HR-CESM is larger than in LR-CESM due to the presence of an eddying ocean.

\subsection{Surface freshwater fluxes}

The Atlantic is a net evaporative basin, and Fig. 6 shows maps of the total surface freshwater flux, $F_{\text {surf }}$, and its major contributing components: precipitation $(P)$ and evaporation $(E)$. In addition, $F_{\text {surf }}$ comprises runoff from land $R$ and ice, as well as sea ice melt (brine rejection) which, from here on, are all defined as positive (negative) freshwater fluxes into the ocean. Precipitation occurs mainly in the ITCZ region (with stronger maxima in HR-CESM), over the Gulf Stream, and in the midlatitude storm tracks. In the HR-CESM (LRCESM) CTRL simulation between $34^{\circ} \mathrm{S}$ and $60^{\circ} \mathrm{N}$, there is a net freshwater loss of $0.85(0.93) \mathrm{Sv}$ which is relatively large 

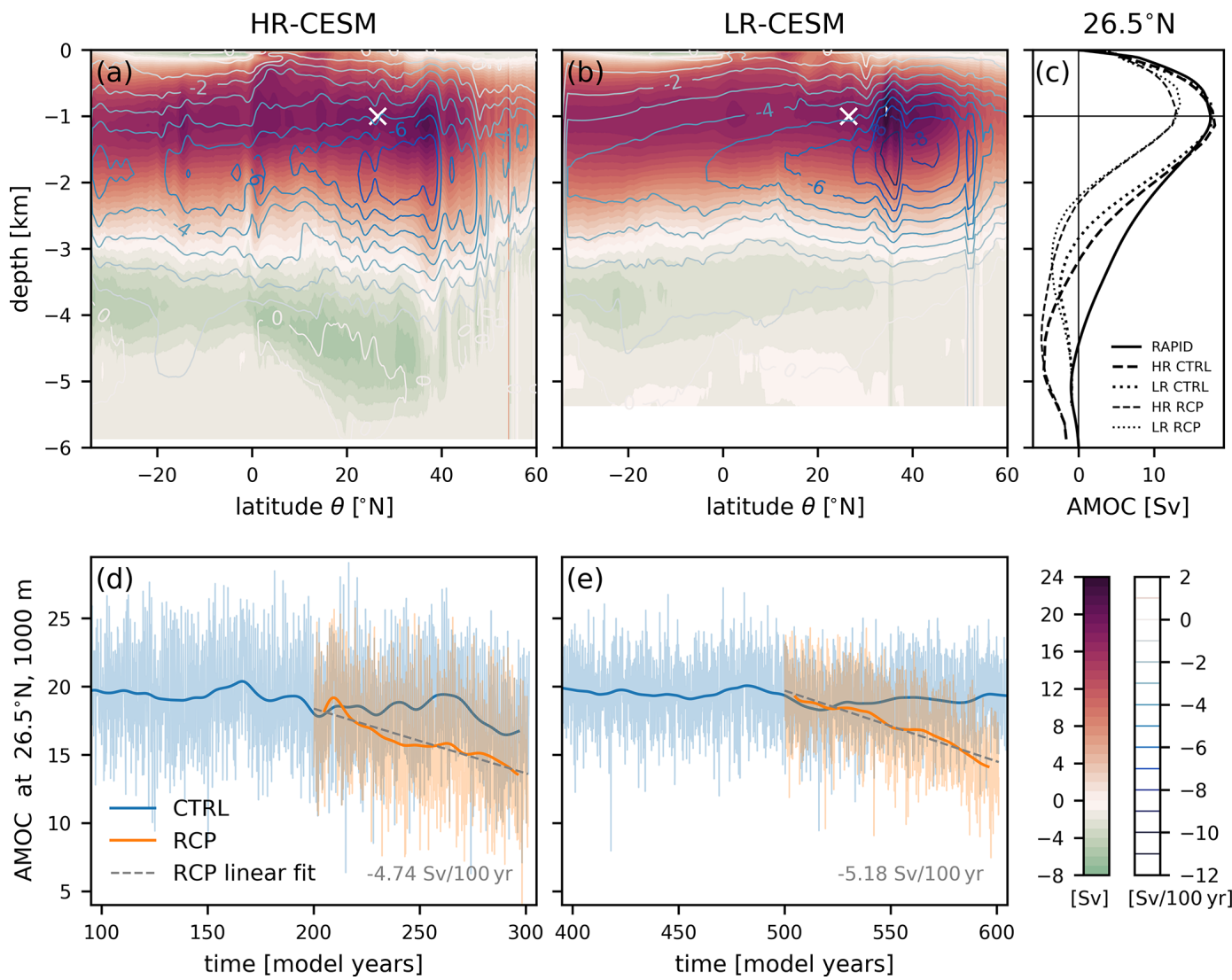

Figure 5. AMOC mean streamfunctions $\psi(\theta, z)$ of the HR-CESM (a) and LR-CESM (b) CTRL simulations together with the linear trends as contour lines every $1 \mathrm{~Sv}$ per century. At $26.5^{\circ} \mathrm{N}$ and $1000 \mathrm{~m}$ depth, the white crosses mark the location of AMOC strength whose time evolution is depicted in panels (d) and (e). Panel (c) compares the modeled CTRL mean streamfunction profiles at $26.5^{\circ} \mathrm{N}$ (thick dashed/dotted) to the RAPID observations (solid) and also presents the changed streamfunction after 100 years in the RCP simulation (thin dashed/dotted). Monthly (thin) and 10-year low-pass-filtered (thick) AMOC time series of the HR-CESM (d) and LR-CESM (e) CTRL (blue) and RCP (orange) simulations. The linear trends are indicated by dashed gray lines and their values are written in the lower right.

compared to the CMIP5 freshwater loss (e.g., $0.48 \pm 0.13 \mathrm{~Sv}$ in the historical multi-model mean in Fig. 6 of Skliris et al., 2020). Evaporation is strongly tied to SSTs (cf. Figs. 1a, b, c and $6 \mathrm{e}, \mathrm{f}$ ) with most occurring in the subtropical gyres and at the above-zonal-average SSTs of the western boundary currents and their extensions. Runoff occurs from all coasts bordering the Atlantic and is artificially distributed over larger areas surrounding the river mouths in the model which is visible in the total freshwater flux subplots of Fig. 6.

The forced freshwater flux trends in Fig. 6 reveal the general intensification of the hydrological cycle as SSTs generally increase (Fig. 1d, e). Total surface freshwater flux linear trends of $-0.14(-0.16) \mathrm{Sv}$ per century between $34^{\circ} \mathrm{S}$ and $60^{\circ} \mathrm{N}$ (see Fig. 9a) in the HR-CESM (LR-CESM) RCP simulation intensify the Atlantic's evaporative nature. The notable exception to this global trend in both simulations is the subpolar gyre where SSTs decline, which results in less evaporation and hence a larger net freshwater flux into the ocean. This reduction in evaporation in the SPG is more pronounced in HR-CESM compared to LR-CESM. Regional differences between the simulations include smaller positive trends along the US east coast due to the different Gulf Stream separation behavior and the related southward extent of the subpolar gyre. The runoff into the Atlantic and Arctic increases almost everywhere with the exception of Amazon basin rivers. In the polar regions, changing freshwater input from melting sea ice is locally significant, e.g., east of Greenland where the total freshwater trends (Fig. $6 \mathrm{c}, \mathrm{d}$ ) are more negative than the evaporative component alone would suggest (Fig. $6 \mathrm{~g}, \mathrm{~h}$ ) despite increases in precipitation (Fig. 6c, d) due to higher atmospheric temperatures. The trends of the surface freshwater flux components are similar on a large scale between HR-CESM and LR-CESM (see Fig. 9).

\subsection{Meridional transport of freshwater}

We decompose the meridional freshwater transport into different terms related to the overturning and azonal gyre circulation as well as an eddy component (equations in Appendix B). Budget term computations are performed on the 

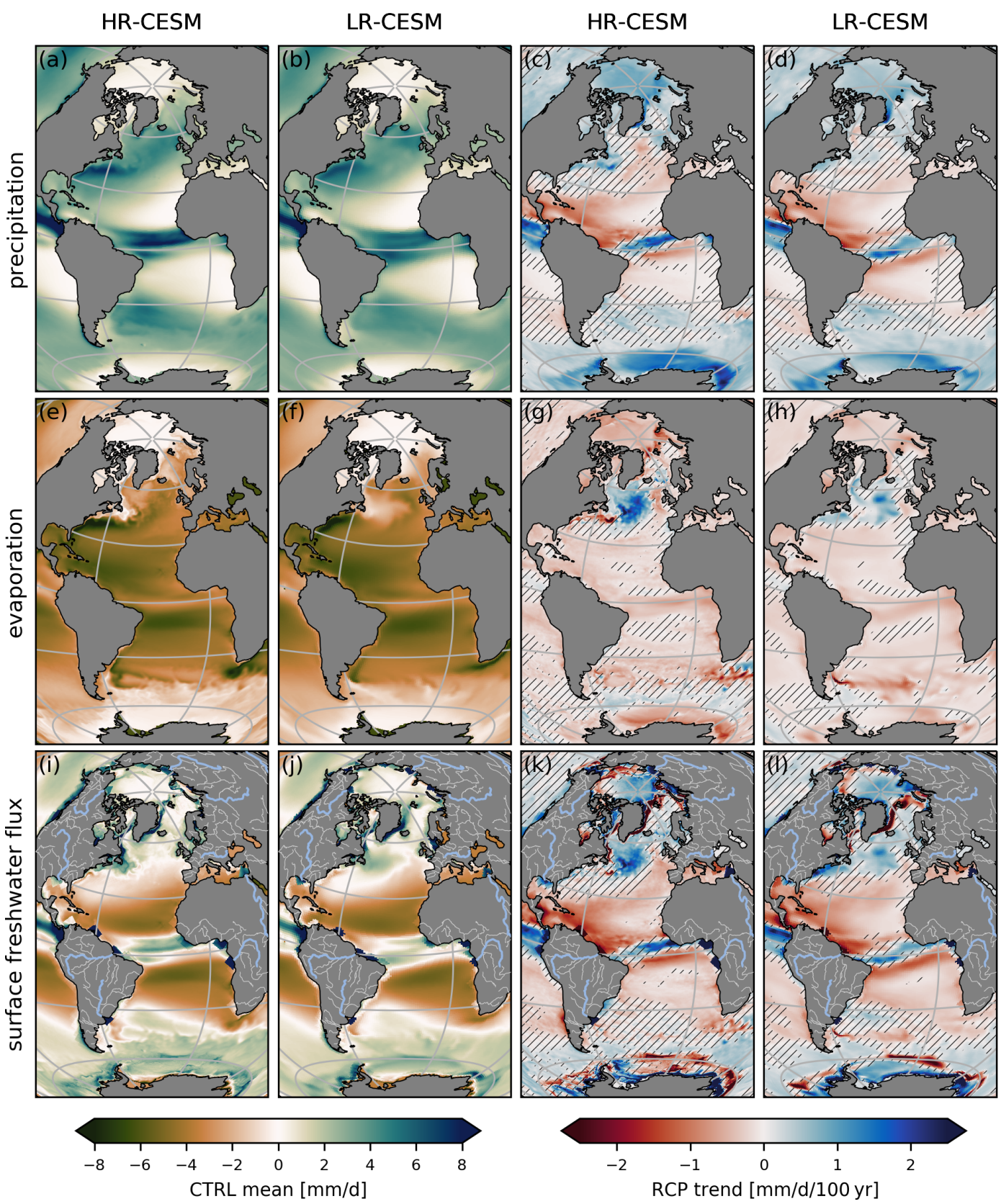

Figure 6. The major freshwater flux components, precipitation $P(\mathbf{a}-\mathbf{d})$ and evaporation $E(\mathbf{e}-\mathbf{h})$, and the total freshwater flux $F_{\text {surf }}(\mathbf{i}-\mathbf{l})$. The means of the HR-CESM (a, e, i) and LR-CESM (b, f, j) CTRL simulations and the linear trends of the HR-CESM (c, g, k) and LR-CESM (d, h, l) RCP simulations. Polygons near river mouths in panels (i)-(l) are areas where runoff is distributed by the ocean model. Hatched areas in the trend maps are not significant at the $5 \%$ level.

original ocean model grid which leads to small differences between model zonal transects and the true parallel of a given latitude in the midlatitudes to high latitudes of the Northern Hemisphere (green lines in Fig. 1b and c). Figure 7 shows the meridional dependence of the different zonally integrated northward freshwater transport components. The figure includes both the 30-year CTRL means and the year-2100 val- ues of the linear RCP trends (top row), as well as the trends themselves (bottom row).

At $60^{\circ} \mathrm{N}$, the total freshwater transport $F_{\text {tot }}$ (red lines in Fig. 7) is negative because relatively fresh water is imported via the Bering Strait into the Arctic where it further freshens mostly due to runoff (Table 2). Despite different volume fluxes at Bering Strait, the freshwater inflow is about the same between the simulations at $0.10 \pm 0.03 \mathrm{~Sv}$ because of 
HR-CESM
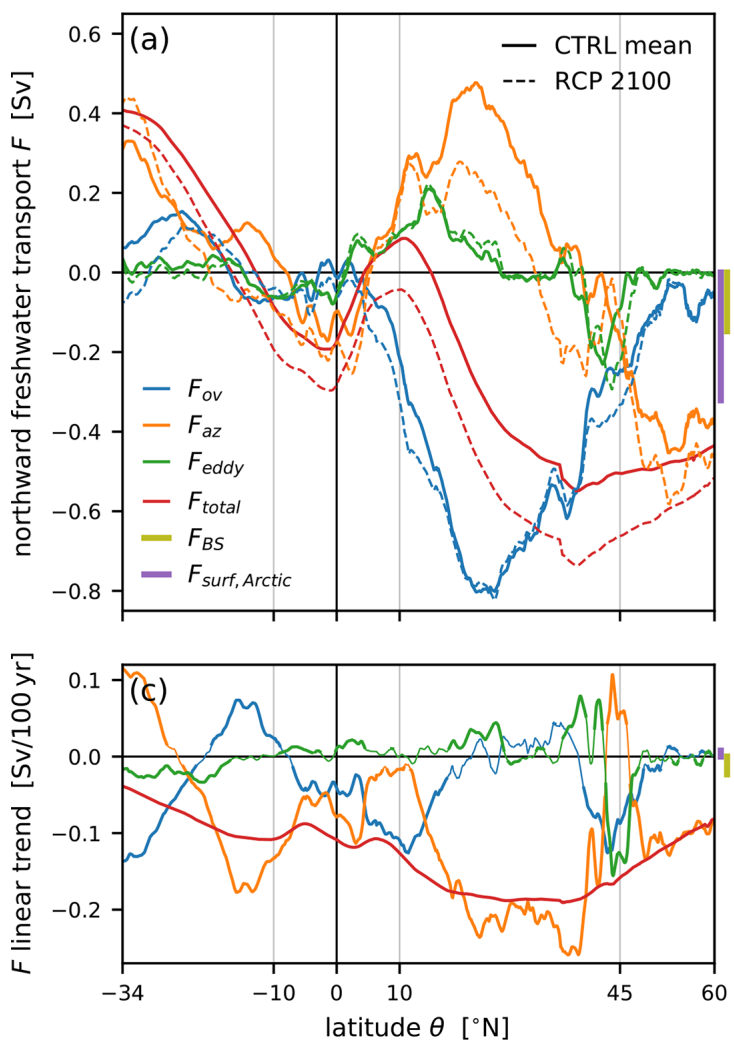

LR-CESM
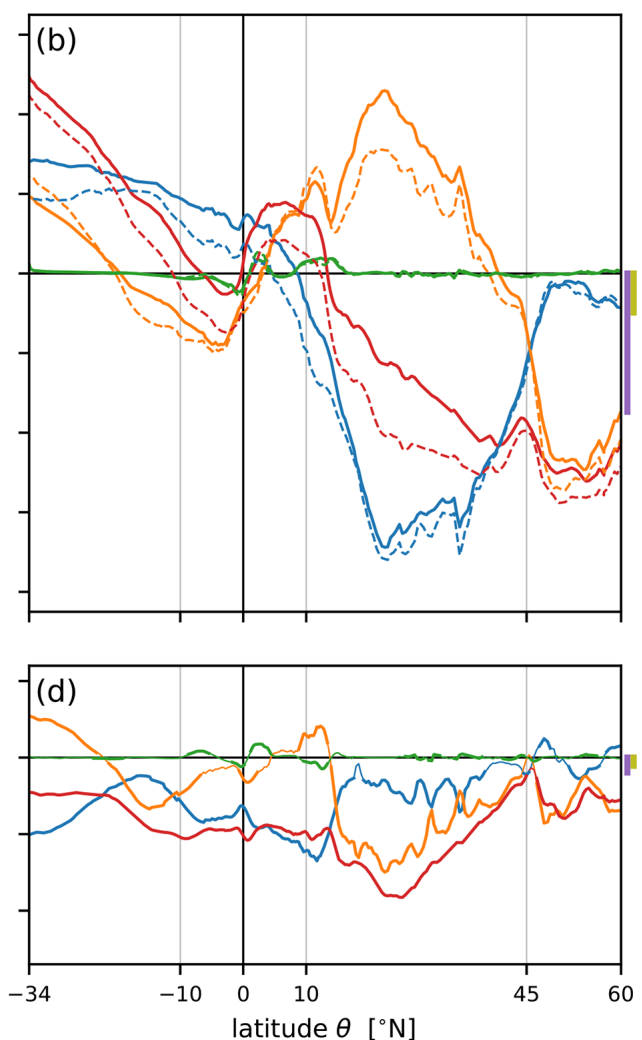

Figure 7. The meridional freshwater transport as a function of latitude $\theta$ for the HR-CESM (a, c) and LR-CESM (b, d) simulations. In panels (a) and (b), solid lines are the means of the 30 CTRL years following the branch-off point and dashed lines are the year-2100 values of the linear RCP fit. The total transport terms (red) are decomposed into an overturning (blue), an azonal gyre (orange), and an eddy contribution (green). Panels (c) and (d) show the linear trends separately. Significant trends (at the $5 \%$ level) are thick, while insignificant trends are only thin. Vertical bars to the right of the panels illustrate the Arctic surface flux in the Arctic (purple) and the Bering Strait inflow (olive) of freshwater.

the stronger fresh bias of the LR-CESM simulation (cf. Table 2, Bering Strait salinity bias in Fig. $3 \mathrm{~b}$ and c, and vertical lines in Fig. 7). The Arctic is a net precipitative basin, in part due to its extensive catchment area, resulting in even more freshwater entering the Atlantic at $60^{\circ} \mathrm{N}$. In the subpolar gyre and the ITCZ, i.e., in latitudes of net precipitation, freshwater diverges (i.e., $\partial F_{\text {total }} / \partial \theta>0$ ), while net evaporation in the subtropical gyres results in freshwater convergence by the oceanic transport. Under the RCP forcing scenario, the total freshwater flow is more southward because more freshwater enters at $60^{\circ} \mathrm{N}$ primarily due to increased net precipitation (including runoff) in the Arctic. Generally, meridional gradients of the total transport in precipitative and evaporative latitudes increase as a result of the enhanced hydrological cycle. Notable differences between the HR- and LR-CESM $F_{\text {tot }}$ are at the STG-SPG boundary at $45^{\circ} \mathrm{N}$, where the LRCESM $F_{\text {tot }}$ does not exhibit the negative transport trend of the HR-CESM $F_{\text {tot }}$ and the meridional position of the tropical freshwater transport divergence related to the southward- biased ITCZ position of LR-CESM. In the following, we take a closer look at these two differences.

The AMOC carries both relatively salty surface waters and fresh Antarctic Intermediate Water northward and salty North Atlantic Deep Water south. The overturning freshwater transport $F_{\text {ov }}$ (blue lines in Fig. 7) thus depends on the vertical distribution of the zonally averaged salinities relative to the depth of the overturning cell (cf. Figs. 3 and 5). Without changes to salinity, a weakening AMOC would reduce the overturning transport, and with a constant AMOC, the intensifying hydrological cycle would lead to enhanced meridional gradients in the transport across precipitative and evaporative parts of the ocean. With the weakening AMOC under the RCP scenario, the $F_{\mathrm{ov}}$ trend is negative everywhere in LR-CESM, while the HR-CESM $F_{\text {ov }}$ trend is not latitudinally coherent in its sign. The HR-CESM $F_{\text {ov }}$ decrease around $40-50^{\circ} \mathrm{N}$ is caused by the northward migration of the boundary between the subtropical and subpolar gyres. The decrease in the overturning transport has some of its largest expression at $34^{\circ} \mathrm{S}$, and the salinity stratification bias of the 
South Atlantic (Fig. $3 \mathrm{j}$ ) results in a positive $F_{\text {ovS }}$ bias which is more pronounced in LR-CESM compared to HR-CESM.

In the absence of eddies, the decomposition of the total flow into the overturning and azonal component depends on the azonal nature of the velocity and salinity fields. Both the North and South Atlantic subtropical gyres transport freshwater north (orange lines in Fig. 7) due to their opposite zonal asymmetry in salt content near the surface where the majority of horizontal gyre transport takes place (Fig. 3), while the subpolar gyre transports freshwater south. Boundary currents, which comprise an important part of the azonal flow, are better resolved in the HR-CESM simulation (cf. Figs. 1, 2, 3, and 4). Under the climate change scenario, the azonal freshwater transport term $F_{\text {az }}$ generally becomes more southward north of $20^{\circ} \mathrm{S}$ in the STGs and the SPG. The gyre transport trends consist both of a gyre strength signal (approximately the barotropic streamfunction of Fig. 4) and one due to the azonal salinity trend (Fig. 8). The HR-CESM $F_{\mathrm{az}}$ trends are the largest contribution to the total southward freshwater trends. In fact, between $20-40^{\circ} \mathrm{N}$, the HR-CESM $F_{\text {az }}$ trend is so negative due to the strong salinification along the North American Atlantic coast (Fig. 8) that the $F_{\text {ov }}$ trend becomes slightly positive (but not significantly so). This occurs also around $5-20^{\circ} \mathrm{S}$ in the HR-CESM simulation where $F_{\mathrm{az}}$ switches signs under forcing. These negative $F_{\mathrm{az}}$ trends are much weaker in LR-CESM so that the overturning component trend remains latitudinally coherent in its sign.

Eddy transport of freshwater $F_{\text {eddy }}$ (green lines in Fig. 7) is not associated with volume fluxes as they are due to correlations between salinity and flow anomalies, which we define with a cutoff timescale of 1 year, i.e., including the seasonal cycle. Figure B1 in the Appendix shows the effect of using a monthly cutoff timescale. A detailed analysis of the eddy salt transport in the Atlantic revealed that it is associated with two distinct mechanisms (Treguier et al., 2012). First, at the STG equatorward edges, seasonal variations in surface salinity and wind-driven circulation cause eddy transport. Second, at the boundary between the subtropical and subpolar gyres, baroclinic mesoscale eddies are responsible for eddy transport. As expected, in the diffusive LR-CESM, the eddy transport is negligible outside tropical seasonal variability, but in HR-CESM, the eddy freshwater transport $F_{\text {eddy }}$ contributes significantly and brings freshwater polewards in the low latitudes and equatorwards around the Gulf Stream and its extension. The eddy transport thus moves freshwater generally downgradient, which is parameterized in LR-CESM with the Gent-McWilliams scheme as a diffusive salt flux (Gent and McWilliams, 1990). Under the RCP scenario, there is essentially no change in the small LR-CESM eddy transport, but the HR-CESM eddy transport magnitude changes markedly around $45^{\circ} \mathrm{N}$ where the Gulf Stream shifts northward (Fig. 4) and the meridional salinity gradient increases (Fig. 8). In contrast to HR-CESM, freshwater diverges around $40-45^{\circ} \mathrm{N}$ in LR-CESM due to the absence of eddy transport. This LR-
CESM freshwater divergence contributes to the salinity bias (see Fig. 3f).

\subsection{Salinity trends}

In the RCP climate change scenario, the Atlantic's salinity changes significantly as surface freshwater fluxes and transport convergences change, even though these salt storage changes are small compared to the fluxes and their changes. Figure 8 shows the linear trend of the vertically averaged salt content for the surface $(0-100 \mathrm{~m})$ and subsurface (100$1000 \mathrm{~m}$ ) layers. In the forced salinity response, the signature of the enhanced hydrological cycle is imprinted: the upper $1000 \mathrm{~m}$ of the Atlantic south of $45^{\circ} \mathrm{N}$ largely salinifies, in particular in the NA-STG. The freshening of the NA-SPG is also a consequence of the weakening AMOC and the associated warming hole (Menary and Wood, 2018). The surface subpolar gyre freshens uniformly in the LR-CESM simulation, but the subsurface shows largely insignificant trends. In HR-CESM, only the eastern SPG freshens down to $1000 \mathrm{~m}$ but salinifies in the East and West Greenland as well as Labrador currents bringing salt into the western SPG. This is the result of advection of salinifying waters from the central Arctic north of Greenland and Svalbard. While the Arctic surface layer between the Bering Strait and the North Pole becomes fresher in both simulations due to enhanced net precipitation including runoff (Fig. 6), the subsurface salinifies strongly in HR-CESM enhancing stratification. In the Southern Hemisphere, enhanced runoff from Africa decreases the salinity in the eastern SA-STG, whereas decreasing runoff from South America enhances the salinification downstream of the Brazil and North Brazil currents (see Fig. 6).

The zonal gradient of the salinity trends of the upper $1000 \mathrm{~m}$ in Fig. 8 is generally westward equatorward of $45^{\circ}$ and more pronounced in HR-CESM. This leads to more azonal northward salt and southward freshwater transport by the North Atlantic subtropical gyre and where the southward Angola Current carries enhanced runoff from tropical Africa southward (Fig. 6k, 1). South of $25^{\circ} \mathrm{S}$, the trend enhances the existing zonal salinity gradient resulting in strengthened azonal transport components (cf. Figs. 3, 7, and 8). The zonal salinity gradient at $34^{\circ} \mathrm{S}$ is opposed by surface freshwater flux trends at this latitude (Fig. 6k-1). This is stronger in LRCESM compared to HR-CESM (Fig. 6) where it leads to a weaker enhancement of the azonal transport components.

\subsection{Freshwater budget}

In order to gain insight into regional changes, we evaluate the freshwater budget over several regions of the Atlantic and Arctic, which is formulated as

$\frac{\mathrm{d} \bar{W}}{\mathrm{~d} t}=F_{\nabla}+F_{\text {surf }}+F_{\text {mix }}$,

where the change in freshwater storage over time $\mathrm{d} \bar{W} / \mathrm{d} t$ over a region is a consequence of the freshwater convergence 

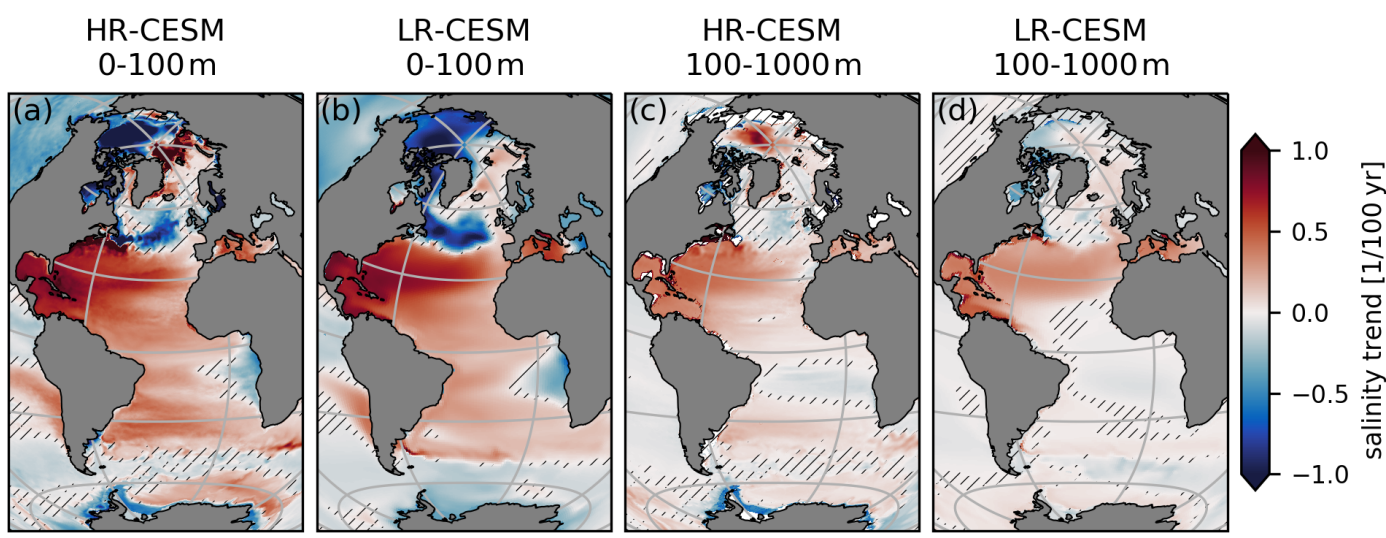

Figure 8. Linear trends of the vertically averaged salinity in the surface $(0-100 \mathrm{~m})$ and subsurface $(100-1000 \mathrm{~m})$ layers under the RCP scenario. Areas where the linear trend is not significant at the $5 \%$ level are hatched.

across the lateral volume boundaries $F_{\nabla}$, surface fluxes $F_{\text {surf }}$, and a residual mixing term $F_{\text {mix }}$ that captures subgrid-scale diffusion (including eddy parameterizations) and errors introduced by our choice of the reference salinity $S_{0}=35$. The freshwater content $W$ of a volume $V$ of ocean water is defined relative to the reference salinity as $\bar{W}=-1 / S_{0} \int(S-$ $\left.S_{0}\right) \mathrm{d} V$. Similarly, freshwater transport across a surface is defined as $F=-\int \frac{S-S_{0}}{S_{0}} u_{\perp} \mathrm{d} A$, where $u_{\perp}$ is the velocity perpendicular to the surface element $\mathrm{d} A$. Surface freshwater fluxes, $F_{\text {surf }}$, are implemented as virtual salt fluxes, $F_{\text {surf }}^{S}$, in the POP2 model and we calculate this flux as $F_{\text {surf }}=$ $-F_{\text {surf }}^{S} / S_{0}$.

Figure 9 presents the freshwater budget terms for each of the regions and the whole Atlantic from $34^{\circ} \mathrm{S}$ to $60^{\circ} \mathrm{N}$ (boundaries as green lines in Fig. 1b, c). Figure 9a is a summary of the tendency and main freshwater flux terms into the ocean as in Eq. (1), panel (b) presents the constituent components in more detail with trends indicated, and panel (c) focuses on the trends of panel (b). The mean values of the CTRL simulations are represented by bars and the 100-year linear trends by arrows. The summary plots in Fig. 9a show how the subtropical gyres are net evaporative and ocean currents converge freshwater there (negative purple $F_{\text {surf }}$ and positive red $F_{\nabla}$ ). On the other hand, both the ITCZ and the NA-SPG gain freshwater through surface fluxes. Here, the freshwater transport divergence (red) is much smaller in magnitude compared to the STG freshwater convergences both due the smaller areas and flux densities (cf. Figs. 1 and $6 \mathrm{i}, \mathrm{j}$ ), and the STGs dominate the signal of the whole Atlantic from $34^{\circ} \mathrm{S}$ to $60^{\circ} \mathrm{N}$. The freshwater reservoir tendency term $\mathrm{d} \bar{W} / \mathrm{d} t$ (cyan) is small compared to the other terms. However, for example, for the whole Atlantic between $34^{\circ} \mathrm{S}$ and $60^{\circ} \mathrm{N}$, the tendency term is crucial in closing the budget as the trends of the transport convergence, $-\nabla F_{\text {tot }}$, are smaller than the opposing trends in the surface fluxes. Full-depth regionally integrated salt content trends are very similar between the simulations, with the largest salt con- tent increase in the NA-STG (cf. Figs. 9a and 8). The mixing term $F_{\text {mix }}$ (brown) is negligible in HR-CESM but sizable in LR-CESM where it includes the parameterized diffusion by eddy fluxes which act downgradient, thus adding freshwater to the saltier, evaporative STGs. The barotropic and hence total salt transport is southward everywhere due to the import through the Bering Strait which is larger in HR-CESM, while the barotropic freshwater transport term sign and magnitude depend on the choice of $S_{0}$ (Schauer and Losch, 2019).

The top vertical bars of Fig. 9b show the major surface freshwater flux terms, whereas the total (purple) is also presented in the summary plot above (Fig. 9a). As discussed with the surface flux maps (Fig. 6), both the means of the CTRL simulations (bars) and the RCP trends (attached arrows) are similar between the simulations given that the exact numbers depend on the choice of bounding latitude. South of $45^{\circ} \mathrm{N}$, all chosen regions experience more evaporation than precipitation (Fig. 6), but in the ITCZ there is net freshwater flux into the ocean due to a large runoff especially from the Amazon and Congo rivers. The strongest trends exists in the NA-STG, but marked differences between the simulations' freshwater input trends exist only in the midlatitudes and high latitudes. In the SPG, the total freshwater input (purple) increases by approximately $20 \%$ in both the HR- and LRCESM, but the HR-CESM experiences a stronger reduction in evaporation because of the lower SST trends (Fig. 1) which is offset by stronger runoff. In the Arctic, the HR-CESM freshwater input decreases slightly by $2 \%$, while the LRCESM input increases by $5 \%$. These relatively small numbers conceal a much larger enhancement of the HR-CESM hydrological cycle with precipitation (evaporation) increasing $55 \%(45 \%)$, while the LR-CESM precipitation (evaporation) only increases by $37 \%$ (24\%).

The horizontal bars of Fig. 9b show the meridional transport components and bottom vertical bars their convergences. The total convergence (red) is also shown in the summary plot above (Fig. 9a). In steady state, the tendency term (cyan) 

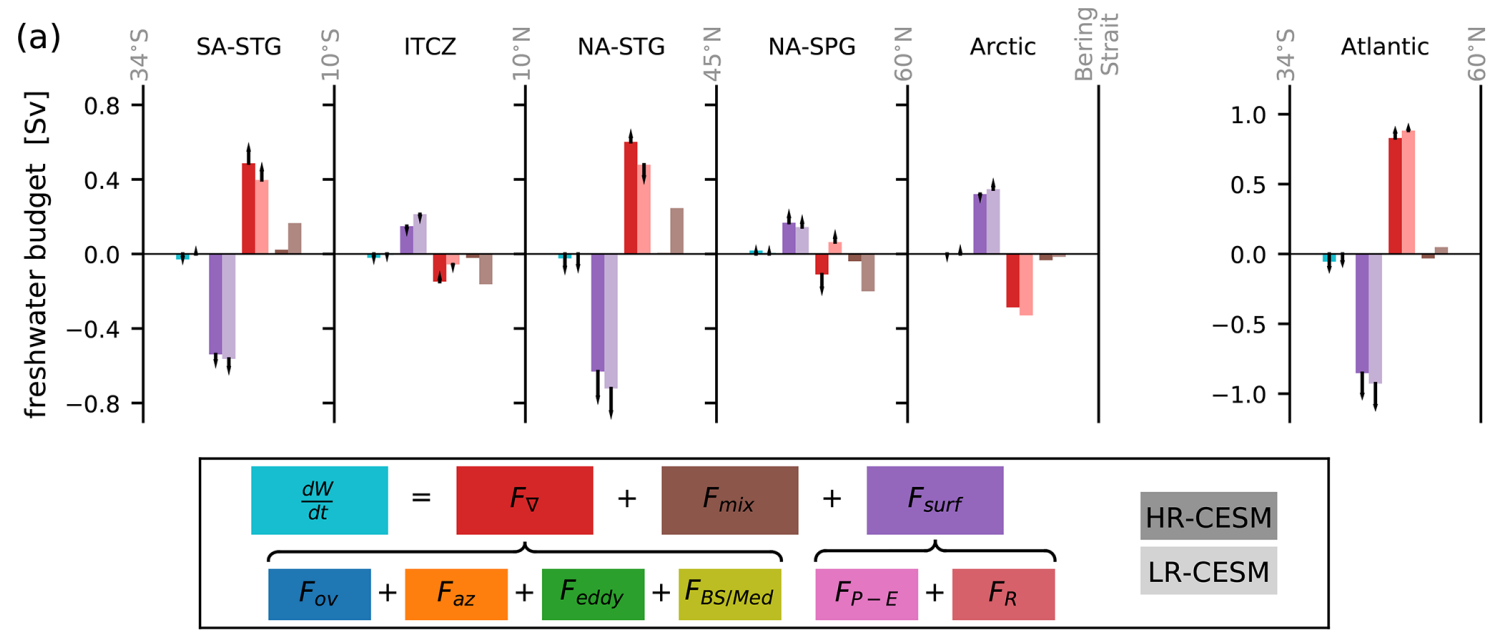

(b)

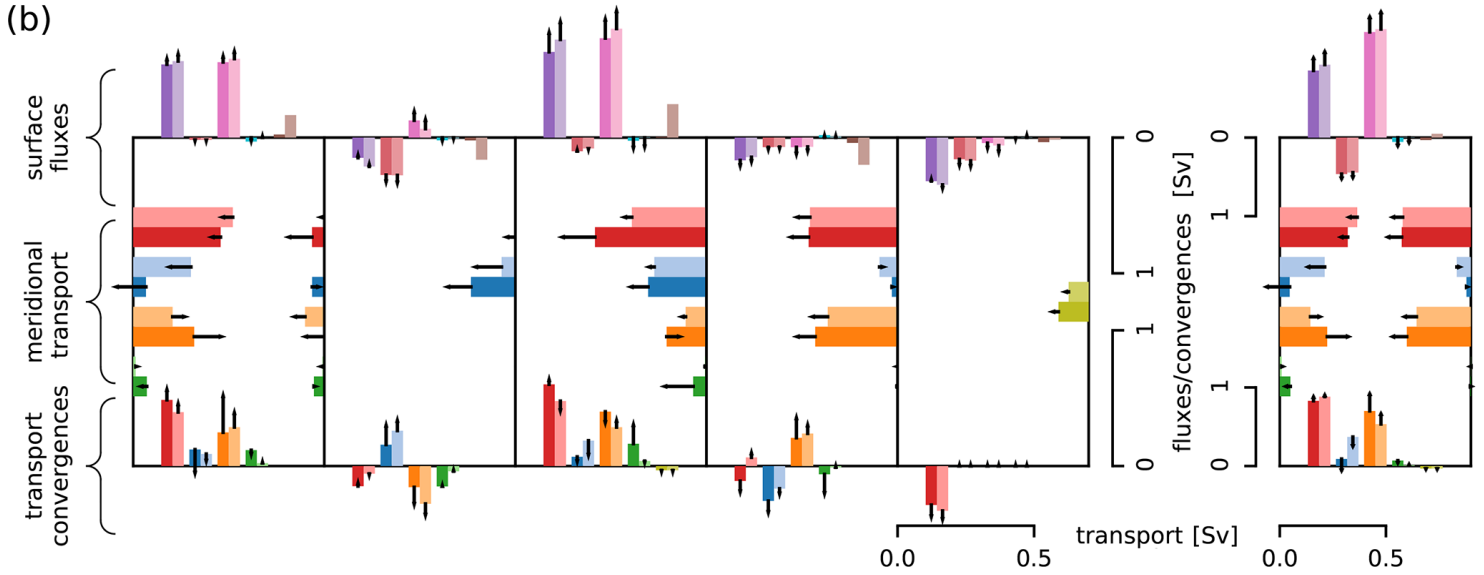

(c)

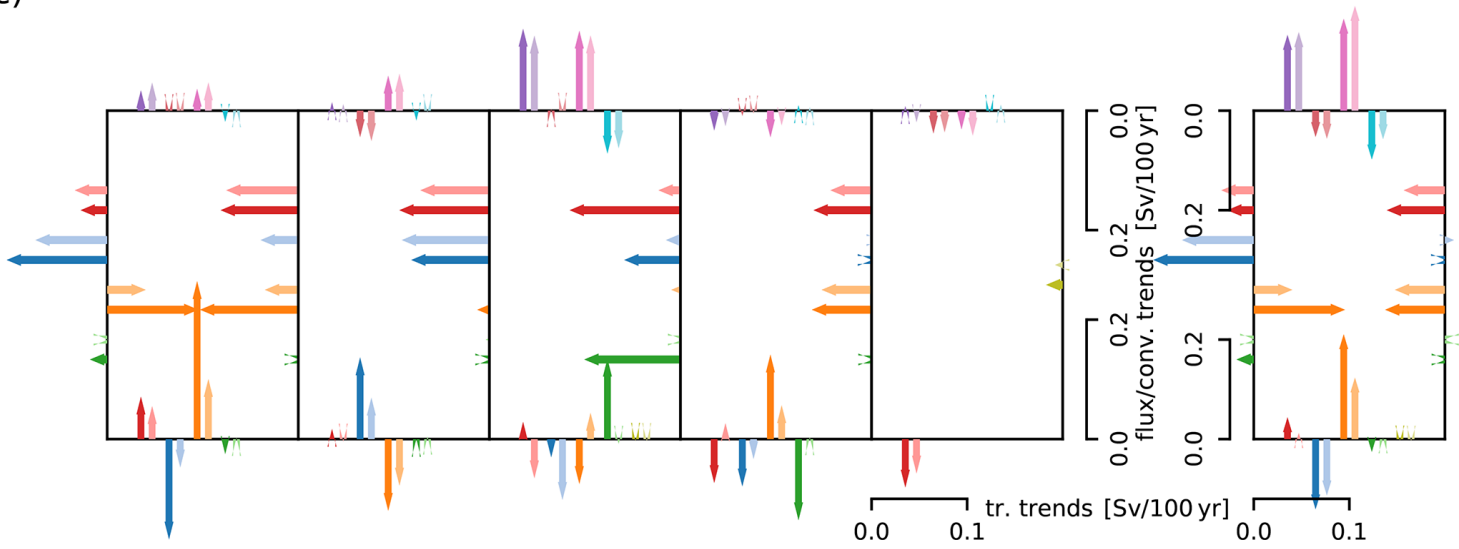

Figure 9. Integrated freshwater budget (Eq. 1) for different zonal bands of the Atlantic. The boundary latitudes (gray) are shown in Fig. 1. Bars are the CTRL simulation averages, and arrows indicate the linear change in the year 2100 of the RCP simulations. Panel (a) summarizes the freshwater budget for the regions with the terms of Eq. (1) with darker (lighter) colors representing HR-CESM (LR-CESM). The notation is explained in Appendix $\mathrm{B}$, and $\Delta \bar{W}$ is the change in freshwater content over 30 years of the CTRL simulations and 100 years of the RCP simulations. Panel (b) shows the freshwater budget terms in detail, where the horizontal bars represent the advective transport across the meridional boundaries with their convergence indicated by the vertical bars at the bottom. Additionally, inflows from the Bering Strait and the Mediterranean are shown. The bars at the top represent surface fluxes, the freshwater content change over time, as well as the mixing term, and all bars are oriented such that inward-pointing bars indicate addition of freshwater. Note that the vertical scale of the top and bottom bars is identical (if reversed), but the horizontal scale is different, as are the scales for the individual regions and the whole Atlantic. 
$\mathrm{d} \bar{W} / \mathrm{d} t=0$, and the total oceanic freshwater convergence (red) compensates for the sum of the surface fluxes (purple). The magnitude of the regional convergences (red) is generally smaller for LR-CESM compared to HR-CESM. The HR- and LR-CESM differences of the overturning (blue) vs. azonal (orange) convergence decomposition offset each other in the STGs, the ITCZ, and the Atlantic as a whole, resulting in the same sign of the total transport convergence (red). Only in the SPG does the sign of the total convergence differ as the overturning convergence is stronger and the azonal divergence is weaker in HR-CESM, and the mixing term captures the parameterized eddy transport in LR-CESM.

Figure $9 \mathrm{c}$ focuses on the trends of the transport terms while using the same layout as Fig. 9b. Under the RCP scenario, the extreme strengthening of the HR-CESM eddy transport (green) at $45^{\circ} \mathrm{N}$ is related to the northward shift of the Gulf Stream under forcing (see Fig. 7; Yang et al., 2020). Figure B1 in the Appendix shows that this negative eddy trend at $45^{\circ} \mathrm{N}$ consists to a large degree of a seasonal signal. The trends in the overturning and azonal convergence trends offset each other (except in the HR-CESM NA-STG with its strong growth in eddy convergence), indicating a change in the zonal salinity distribution (see Fig. 8).

\subsection{AMOC stability indicators}

The freshwater import (export) by the AMOC constitutes a negative (positive) feedback. The freshwater convergence by the overturning circulation $\Sigma=F_{\mathrm{ovS}}-F_{\mathrm{ovN}}$, where $F_{\mathrm{ovS}}$ and $F_{\text {ovN }}$ are located at $34^{\circ} \mathrm{S}$ and $60^{\circ} \mathrm{N}$, respectively, has been suggested as an indicator for an AMOC multiple equilibrium regime (Dijkstra, 2007; Huisman et al., 2010; Liu et al., 2014). Figure 10 shows the evolution of these indicators together with the azonal freshwater transport at $34^{\circ} \mathrm{S}$, $F_{\mathrm{azS}}$, for both the CTRL and RCP simulations. Both the HRand LR-CESM CTRL simulations initially equilibrate with increasing $F_{\mathrm{ovS}}$ values (blue). At the point where the RCP simulations are branched off, $F_{\mathrm{ovS}}$ appears to have reached an equilibrium as the concurrent CTRL time series are statistically stationary. Despite a very similar overturning strength (Fig. 5), the LR-CESM CTRL $F_{\text {ovS }}$ values are significantly higher due to the stronger vertical salt bias (Fig. 3). Noneddying CMIP5 models have a positive bias in the $F_{\text {ovS }}$ sign and may hence be too stable; much of this bias is a result of the salinity bias with fresh surface anomalies south of $20^{\circ} \mathrm{N}$ and salty anomalies elsewhere in the Atlantic (Mecking et al., 2017). Artificially replacing the CMIP5 model salinities by observed values as in Mecking et al. (2017) reduces $F_{\text {ovS }}$ to negative values. The CTRL azonal component $F_{\text {azS }}$ (orange) equilibrates faster than the overturning component as it relates to the shallower transport by the wind-driven STGs. The total freshwater transport at $60^{\circ} \mathrm{N}$ is almost identical between the simulations and consists predominantly of the azonal component (cf. Figs. 7 and 9), but the exact azonal vs. overturning decomposition differs such that the LR-CESM
$F_{\text {ovN }}$ magnitude is larger than the HR-CESM $F_{\text {ovN }}$ magnitude, resulting in a larger offset in $\Sigma$.

In response to the RCP forcing, both HR- and LR-CESM exhibit negative $F_{\mathrm{OVS}}$ trends at -0.14 and $-0.10 \mathrm{~Sv}$ per century, respectively. The $F_{\mathrm{ovS}}$ values decrease because the salinity trends offset the fresh bias near the surface (see Figs. 3 and 8). The $\Sigma$ value is also plotted in Fig. 10 and its trend is evidently dominated by $F_{\text {ovS }}$, while $F_{\text {ovN }}$ barely changes under forcing (Fig. 7). The azonal gyre component $F_{\text {azS }}$ also evolves in response to the forcing (cf. Fig. 8) and is connected to $F_{\text {ovS }}$ through the overall freshwater budget (Cimatoribus et al., 2012). Its change compensates the change in $F_{\text {ovS }}$ completely in HR-CESM and only half of it in LR-CESM. Both $F_{\text {ovS }}$ and $\Sigma$ indicate a shift into the unstable, multiple equilibrium regime under the RCP forcing in HR-CESM but not LR-CESM.

\section{Summary and discussion}

We analyzed the Community Earth System Model's Atlantic freshwater budget in a high-resolution, strongly eddying ocean component and in a low-resolution, noneddying ocean component indicated here by HR-CESM and LR-CESM, respectively. We compared present-day control simulations (CTRL) with observational data and analyzed changes under a climate change scenario with increasing greenhouse gases (RCP). Previous studies have analyzed the Atlantic freshwater budget's present-day state with strongly eddying ocean models (Treguier et al., 2012) or investigated the freshwater budget under climate change but with coarseresolution ocean models (Drijfhout et al., 2011), but this is the first analysis of the freshwater budget under climate change investigating the effect of strongly eddying oceans. Apart from the ocean horizontal resolution in the CESM, also the atmosphere model component version and resolution differ. However, the mean surface freshwater fluxes are comparable where ocean biases are comparable, and the forced hydrological cycle response is similar between HR- and LRCESM (Fig. 6). In validating the simulations, uncertainty in observations, particularly in the different $P-E$ products (Fig. 2), must be acknowledged (Trenberth et al., 2011). A multidecadal variability signal, significant with respect to a red noise null hypothesis, also exists in the HR-CESM simulation (Jüling et al., 2020). This could potentially influence the results, but the magnitude of the response to the strong $\mathrm{RCP}$ forcing is very large compared to this internal variability.

Increasing the resolution of the ocean component enables more realistic simulation of currents, eddies and overflows, and the circulation features such as the Gulf Stream separation or the Agulhas retroflection are better represented in the HR-CESM simulation (Fig. 4). We find that many ocean biases are reduced in HR-CESM compared to LR-CESM. Although the HR-CESM ocean presents more realistic bound- 


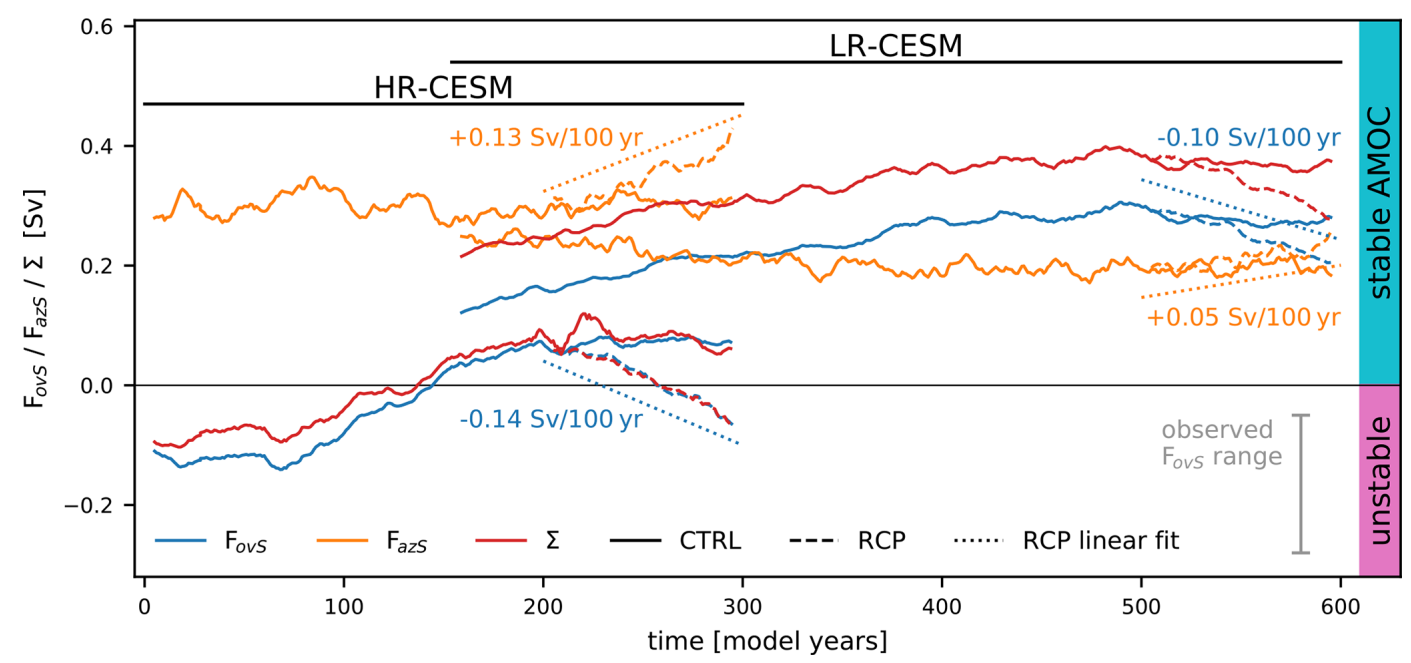

Figure 10. Time series of the annually averaged freshwater import into the Atlantic by the overturning circulation $F_{\text {OvS }}$ at $34^{\circ} \mathrm{S}$ (blue), the azonal freshwater transport contribution $F_{\mathrm{az}}$ (orange), and the overturning freshwater transport divergence between $34^{\circ} \mathrm{S}$ and $60^{\circ} \mathrm{N}, \Sigma$ (red). All available data are shown from the CTRL simulations (solid) together with the RCP simulations (dashed) branching off in year 200 (500) for HR-CESM (LR-CESM). The linear trend values of the RCP simulations are written close to offset linear fits (dotted). The observed $F_{\text {ovS }}$ range (gray) is from Weijer et al. (2019), and the AMOC stability regimes are labeled on the right.

ary conditions to the atmosphere with more energy at smaller spatial and temporal scales (Kirtman et al., 2012), the atmosphere freshwater flux CTRL mean and RCP trends are similar between the two model setups (cf. Figs. 2d, 6, and 9). The large-scale hydrological cycle strengthens similarly with generally warming surface temperatures, the exception being the cooling NA-SPG (Fig. 6). Also the AMOC weakens similarly (Fig. 5) in both RCP simulations, such that any differences in the simulated responses are likely due to the different ocean model resolution. The mean and trend of the ocean freshwater and salt transport, its convergence, and its decomposition differ between HR- and LR-CESM, especially in regions of strong eddy activity (cf. Figs. 7 and 9).

By comparing the CTRL simulations against observations relevant to the freshwater budget, we find that the HR-CESM biases are notably reduced compared to the LR-CESM setup. In particular, we diagnosed reduced biases of SST (Figs. 1, A1), the precipitation minus evaporation fluxes (Figs. 2, A2), and the 3-D Atlantic salinity distribution (Figs. 3, A3). Two phenomena contribute to the strong meridional LR-CESM surface salinity bias gradient that also plagues other coarseresolution models (Mecking et al., 2017): first, an unrealistically large import of too-fresh surface waters from the southwest Indian Ocean into the South Atlantic (cf. Figs. 4 and A3), and second, the southward shift of the ITCZ due to a more asymmetric Atlantic meridional SST bias (cf. Figs. 1 and 2). The structure and magnitude of the HR- and LRCESM CTRL meridional freshwater transport terms (Fig. 7) are generally similar to those found in earlier studies with non-eddying models (Yin and Stouffer, 2007; Skliris et al., 2020) and eddying models (Mecking et al., 2016).
Despite similar atmospheric changes and AMOC slowdown, there are many notable differences between the HRand LR-CESM simulations. Forced circulation changes differ in that the HR-CESM Gulf Stream moves north and the SPG circulation strength trends show a dipole pattern as opposed to a large-scale weakening in the LR-CESM simulation (Fig. 4). Also, Arctic surface freshwater fluxes change differently, and the sea ice response may be underestimated due to low-biased heat transport into the Arctic in the LRCESM simulation (Fig. 9). The large-scale structure of the $F_{\text {tot }}$ transport is similar and so is the forced response, with the exception of the STG-SPG boundary around $45^{\circ} \mathrm{N}$ where the LR-CESM shows no trends in any transport component, but the HR-CESM exhibits a large negative $F_{\text {tot }}$ trend, due in equal parts to the eddy and overturning components (Fig. 7). The decomposition between overturning and azonal components differs between the HR-CESM and LR-CESM simulations as the azonal quality of both the salinity and velocity fields differs. Eddy fluxes are significant at the northern and southern boundaries of the STGs (Treguier et al., 2012, 2014).

The evolution of the AMOC under climate change is of great interest, and based on our results, and those of others, simulating strongly eddying oceans does not appear to systematically influence that response (Gent, 2018; Hirschi et al., 2020). The CTRL AMOC strength and reduction under the RCP scenario are almost identical between the simulations with a reduction of $\sim 5 \mathrm{~Sv}$ in 100 years from $18 \mathrm{~Sv}$ which compares well with the observed AMOC strength at the RAPID array at $26.5^{\circ} \mathrm{N}$ of $17.0 \mathrm{~Sv}$ (Smeed et al., 2018). The reduced heat transport by the AMOC into the subpolar gyre constitutes a positive atmospheric feedback in that 
evaporation is reduced, freshening the surface in the sinking regions. The salt advection feedback is another positive AMOC feedback, and it can lead to multiple equilibria if the overturning circulation exports freshwater from the Atlantic basin. A weakened AMOC would export less freshwater which would ultimately further suppress deep water formation in the North Atlantic, and vice versa. As it is not possible to prove the existence of multiple AMOC equilibria with modern coupled climate models due to the high dimensionality and the prohibitive computational cost of equilibrating the ocean circulation after millennia, it is desirable to use scalar indicators based on simpler models. The import of freshwater to the Atlantic by the overturning circulation $F_{\mathrm{ovS}}$ can hence provide further insight into the question of AMOC stability if atmospheric feedbacks are negligible (Huisman et al., 2010). Observations suggest a negative $F_{\text {ovs }}$ between -0.28 and $-0.05 \mathrm{~Sv}$ at present (Weijer et al., 2019). Due to their salinity bias at $34^{\circ} \mathrm{S}$, both HR-CESM and LR-CESM CTRL simulations import freshwater into the Atlantic, but this bias is significantly reduced in HR-CESM (Figs. 3, 10). This bias, from which all coarse-resolution CMIP5 models suffer (Mecking et al., 2017; Gent, 2018), is countered by salinification of the surface under radiative forcing decreasing the $F_{\mathrm{ovS}}$ value which indicates decreasing stability.

The ocean mean state as well as the forced response are different with higher resolution, but from our two RCP simulations we cannot discern any systematic effect on AMOC response to climate change as it is a large-scale flow feature and the correct simulation of the sinking regions is likely more important (Hirschi et al., 2020; Jackson et al., 2020). Yet due to the reduced salinity biases in particular at $34^{\circ} \mathrm{S}$ in HRCESM, the indicator of the multiple equilibrium regime $F_{\text {ovS }}$ suggests that the salt advection feedback can destabilize the AMOC in the 21st century. However, the HR-CESM freshwater overturning transport response is meridionally incoherent, and hence freshwater may not be simply advected northward with the AMOC. As the transport decomposition is further complicated by an eddy term, it is questionable whether the simple indicator is useful for quantifying the salt advection feedback and it may have to be adapted. In the absence of eddy terms and changes in the salt reservoirs, the overturning and azonal components must balance, which was used by de Vries (2005) to change the sign of $F_{\text {ovs }}$. By changing the azonal quality of the freshwater surface fluxes at $34^{\circ} \mathrm{S}$ and hence the gyre transport, Cimatoribus et al. (2012) was able to collapse the AMOC without any further changes, suggesting that also this component of the transport must be taken into account when assessing the stability. Furthermore, any interpretation of the $F_{\text {ovS }}$ in short strongly eddy simulations should be undertaken with care. Figure 10 shows that the HRCESM CTRL simulation switches sign from negative to positive $F_{\text {ovs }}$ only after 150 years as the ocean equilibrates.
To conclude, the changes in the Atlantic freshwater budget due to global warming are fairly robust to the resolution improvement from a diffusive to a strongly eddying ocean in CESM. This strengthens trust in using the current generations of coupled climate models (CMIP5, CMIP6) and their AMOC change projections, which are computationally significantly cheaper to perform. On the other hand, the biases in the present-day state are strongly reduced in the strongly eddying ocean version of CESM and hence indicate that better parameterizations are needed in the CMIP5/CMIP6 models to reduce these biases. This reduction can be crucial for assessing the probability of tipping the AMOC under future climate change. 


\section{Appendix A: Additional model-observation comparison}

In this Appendix, we present global maps of the modelobservation comparisons of Sect. 2.2.

Regarding the SST bias world map (Fig. A1), in the HRCESM CTRL simulation, warm biases are located in the high latitudes and the tropical Indo-Pacific and cold biases in the Indo-Pacific subtropical gyres and the tropical and subtropical Atlantic. The LR-CESM CTRL simulation SST bias is more asymmetric around the Equator with large-scale cold biases only in the Northern Hemisphere subtropical gyres and the southern edge of the NA-SPG.
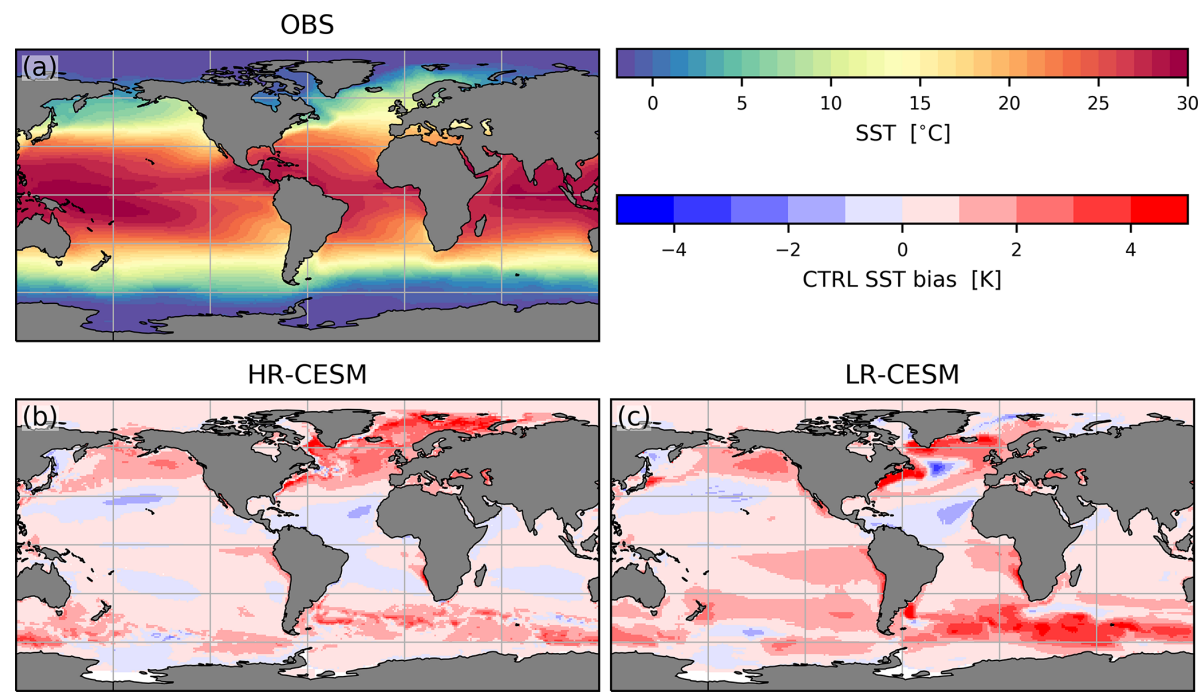

Figure A1. Bias of annual SSTs of the HR-CESM (a, b) and LR-CESM (c) CTRL simulations, like Fig. 1.
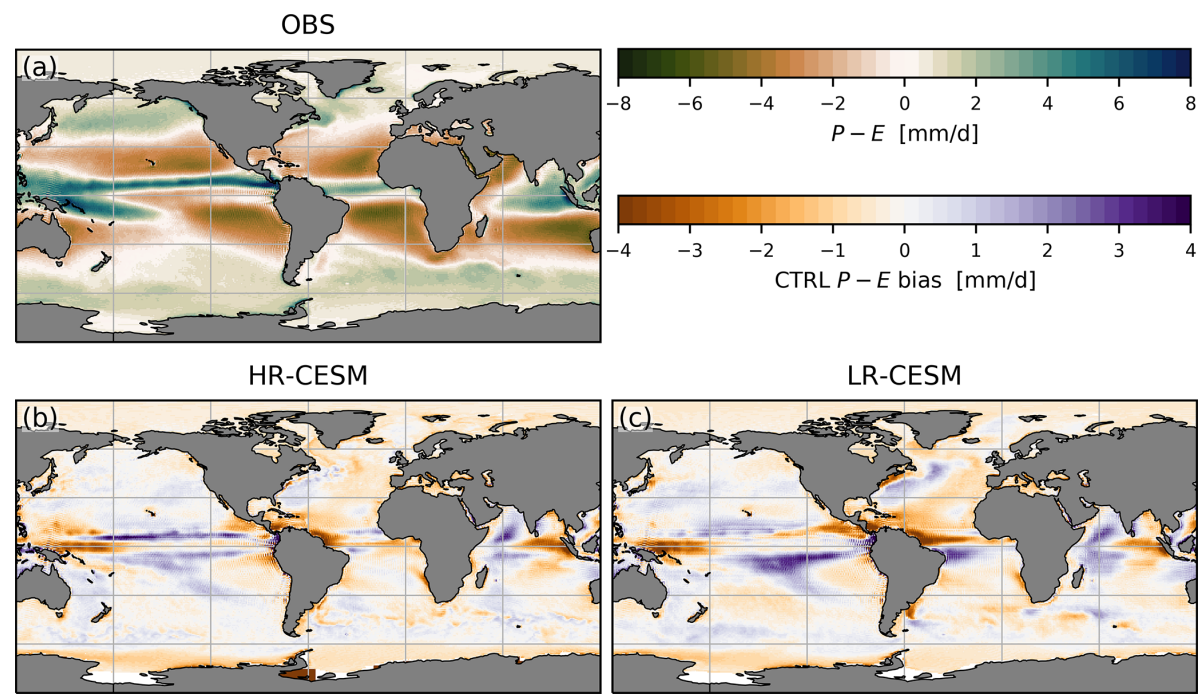

Figure A2. Comparing HR-CESM (a, b) and LR-CESM (c) precipitation to ERA-Interim, like Fig. 2. 

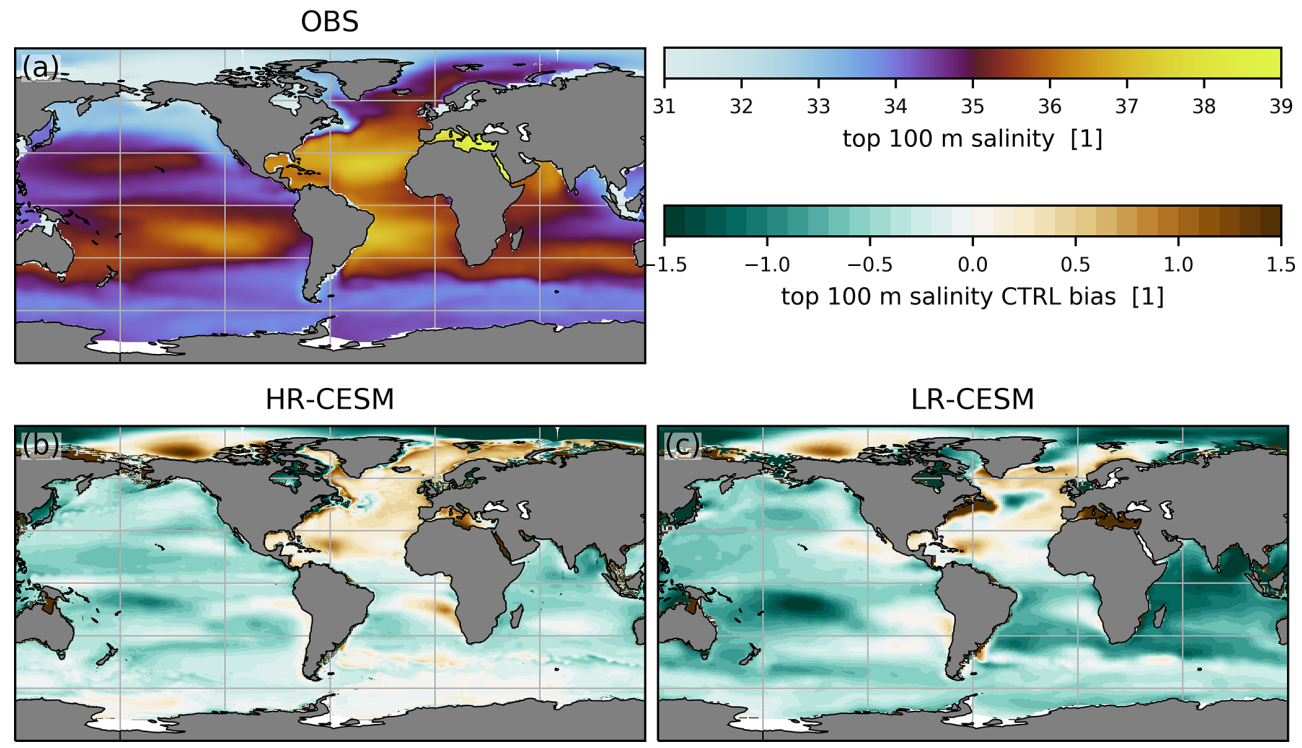

Figure A3. The salinity bias of the upper $100 \mathrm{~m}$, like Fig. 3 .
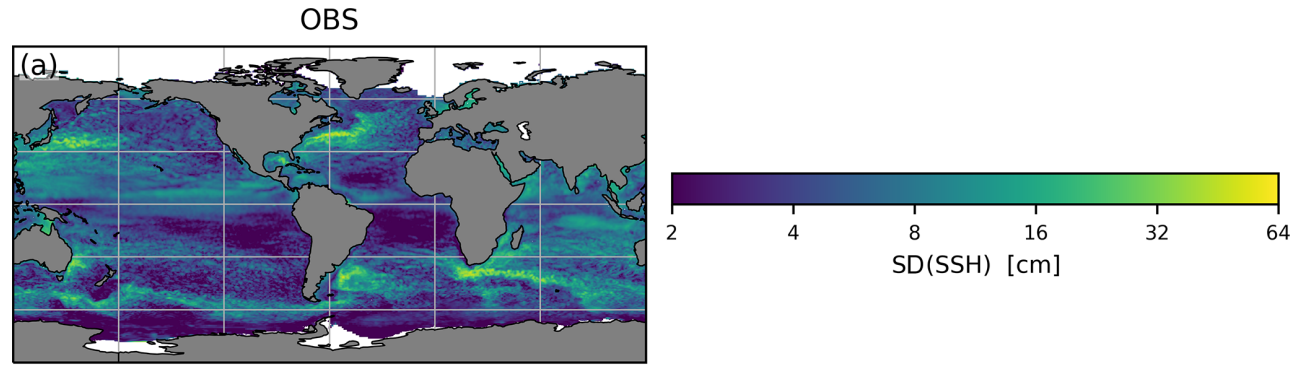

HR-CESM

LR-CESM
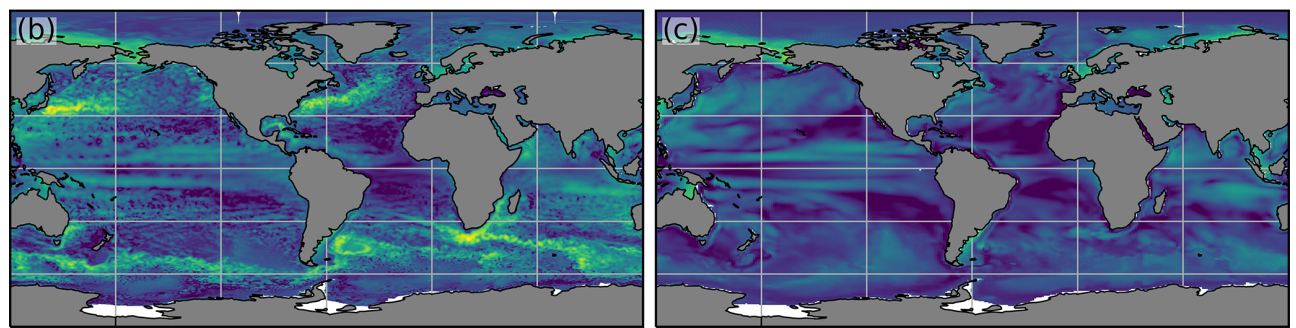

Figure A4. The standard deviation of the observed sea surface height (a) and the modeled dynamic sea level (b, c), like Fig. 4. 


\section{Appendix B: Budget calculation}

As Schauer and Losch (2019) point out, the values of the freshwater flux terms are non-linearly dependent on the chosen reference salinity $S_{0}$. Traditionally, the AMOC bistability question with respect to the salt advection feedback has been framed in terms of freshwater import due to the meridional overturning.

\section{B1 Freshwater budget}

We define freshwater fluxes in the ocean relative to a reference salinity of $S_{0}=35$ in units of $1 \mathrm{~Sv}=10^{6} \mathrm{~m}^{3} \mathrm{~s}$. The freshwater flux budget of an arbitrary full-depth ocean volume is given by Eq. (1), which we repeat here for a selfcontained presentation of the budget calculations:

$\frac{\mathrm{d} \bar{W}}{\mathrm{~d} t}=F_{\nabla}+F_{\text {surf }}+F_{\mathrm{mix}}$

where $\bar{W}=-\frac{1}{S_{0}} \iiint S-S_{0} \mathrm{~d} V$ is the freshwater content of the volume $V$. The first term on the right-hand side, $F_{\nabla}$, is due to the advection of freshwater gradients across the vertical boundary $b$, which is full depth and encloses the volume $V$ :

$F_{\nabla}=\iint u \cdot \nabla W \mathrm{~d} b / \iint \mathrm{d} b$.

The second term is the freshwater flux at the surface comprising precipitation $P$, evaporation $E$, runoff from land $R$ and ice $I$, as well as sea ice melt $M$ (brine rejection $B$ ), which are all defined as positive (negative) freshwater fluxes into the ocean:

$F_{\text {surf }}=P+E+R+I+M+B$.

The last term, $F_{\text {mix }}$, captures diffusion (including eddy parameterizations), errors introduced by the time averaging of the output and the choice of the reference salinity $S_{0}$ and is calculated as a residual:

$F_{\text {mix }}=\frac{\mathrm{d} \bar{W}}{\mathrm{~d} t}-F_{\text {surf }}-F_{\nabla}$

Furthermore, we ignore changes in dynamic sea level in the calculation of $\bar{W}$ such that these small effects are included in $F_{\text {mix }}$.

To ascertain whether a perturbation in the overturning is amplified or damped through the salt advection feedback, the freshwater transport due to the overturning is evaluated at the southern boundary $\left(F_{\text {ovs }}\right)$. In general, the advective term can be divided into a barotropic component $F_{\mathrm{bt}}$, an overturning component $F_{\mathrm{ov}}$, an azonal component due to the gyre circu- lation $F_{\mathrm{az}}$, and an eddy component $F_{\text {eddy }}$ such that

$$
\begin{aligned}
& F_{\nabla}=\left.\left(F_{\mathrm{bt}}+F_{\mathrm{ov}}+F_{\mathrm{az}}+F_{\mathrm{eddy}}\right)\right|_{y=\theta_{S}} ^{\theta_{N}} \\
& F_{\mathrm{bt}}(y)=-\hat{v} \frac{\hat{S}-S_{0}}{S_{0}} \\
& F_{\mathrm{ov}}(y)=-\frac{1}{S_{0}} \int\left[\int_{W}^{E} v^{*} \mathrm{~d} x\right]\left[\langle S\rangle-S_{0}\right] \mathrm{d} z
\end{aligned}
$$

$F_{\mathrm{az}}(y)=-\frac{1}{S_{0}} \int_{-H}^{z} \int_{W}^{E} v^{\prime} S^{\prime} \mathrm{d} x \mathrm{~d} z$

$F_{\text {eddy }}(y)=-\frac{1}{S_{0}} \int_{-H}^{z} \int_{W}^{E}\left(\overline{v\left[S-S_{0}\right]}-\bar{v} \times \bar{S}\right) \mathrm{d} x \mathrm{~d} z$,

where $F_{\nabla}$ is evaluated between the southern and northern boundaries, $\theta_{\mathrm{S} / \mathrm{N}}$. The hat notation $\hat{q}$ of an arbitrary quantity $q$ denotes the section average, $\hat{q}=\iint q \mathrm{~d} x \mathrm{~d} z / \iint \mathrm{d} x \mathrm{~d} z$. In the case of $q=v, \hat{v}$ is the barotropic velocity and $v^{*}=v-\hat{v}$ is the baroclinic velocity. Angled brackets $\langle q\rangle=$ $\int q \mathrm{~d} x / \int \mathrm{d} x$ denote zonal averaging, while primed quantities $q^{\prime}=q-\langle q\rangle$ are deviations from zonal means.

In the specific case of the Atlantic-Arctic freshwater budget, the oceanic advection term can be decomposed into advective freshwater fluxes at a southern and northern boundary, usually at the latitudes of Cape Agulhas at $34^{\circ} \mathrm{S}$ and the Bering Strait at $68^{\circ} \mathrm{N}\left(F_{\mathrm{BS}}\right)$, plus the Mediterranean inflow $\left(F_{\text {Med }}\right)$.

$F_{\text {Med }}=-\frac{1}{S_{0}} \int_{-H}^{z} \int_{\theta_{\text {Med, } \mathrm{S}}}^{\theta_{\text {Med, } \mathrm{N}}} \overline{u\left(S-S_{0}\right)}\left(x=5.5^{\circ} \mathrm{W}\right) \mathrm{d} z \mathrm{~d} y$,

where $u$ is the zonal velocity.

Note that sometimes $F_{\mathrm{ov}}$ is defined to include the barotropic component (e.g., de Vries, 2005):

$F_{\mathrm{ov}}=-\frac{1}{S_{0}} \int \bar{v}\left[\langle S\rangle-S_{0}\right] \mathrm{d} z$.

Equations (B7) and (B11) are equal if the reference salinity is equal to the section average, $S_{0}=\hat{S}$, and the barotropic transport is zero, $F_{\mathrm{bt}}=0$.

Due to the volume-conserving, virtual salt flux formulation of the ocean model, the barotropic meridional volume transport throughout the Atlantic equals that through the Bering Strait (Table 2). The barotropic freshwater transport thus depends only on the section average salinity which is so close to the reference salinity, $S_{0} \approx \hat{S}$, that $F_{\mathrm{bt}}$ is negligibly small compared to the other transport components and hence not shown. 


\section{B2 Eddy-mean decomposition}

To calculate the eddy terms, we use the eddy-mean decomposition of the total flux:

$\overline{x y}=\overline{x y}+\overline{x^{\prime} y^{\prime}}$,

where the overbar $\bar{x}$ denotes a time average, which we choose to be annual so as to include seasonality effects from the eddy term (Fig. B1 compares an annual with a monthly cutoff timescale), and primed quantities $x^{\prime}$ denote eddy terms.

Neither the total nor the eddy freshwater transport terms, $\overline{v\left[S-S_{0}\right]}$ and $-\frac{1}{S_{0}} \overline{v^{\prime}\left[S-S_{0}\right]^{\prime}}$, are part of the model output. However, the total salt transport $\overline{v S}$ is, so that one can calculate the eddy salt transport:

$F_{\text {eddy }}^{S}=\int_{-H}^{z} \int_{W}^{E} \overline{v S}-\bar{v} \times \bar{S} \mathrm{~d} x \mathrm{~d} z$.

The freshwater eddy transport is linearly related to the eddy salt transport:

$$
F_{\text {eddy }}=-\frac{1}{S_{0}} \overline{v^{\prime}\left[S-S_{0}\right]^{\prime}}=-\frac{1}{S_{0}} \overline{v^{\prime} S^{\prime}}=-\frac{1}{S_{0}} F_{\text {eddy }}^{S},
$$

and the total freshwater flux is thus

$F_{\text {total }}=F_{\mathrm{bt}}+F_{\mathrm{ov}}+F_{\mathrm{az}}+F_{\text {eddy }}$.
Figure B1 shows the effect of the cutoff timescale on all transport terms. Only in HR-CESM is the eddy term of relevant magnitude compared to the mean terms. Naturally, the total transport is unaffected, while the mean terms, in particular the azonal term, gain strength at the expense of the eddy term. The HR-CESM eddy term (green line in Fig. B1a) is reduced to roughly half its strength in the ITCZ and the NASTG, while it becomes negligible in the SA-STG. Under climate change, trends in eddy transport are similarly reduced at a monthly cutoff timescale, suggesting that much of the changes in the annual eddy trends are driven by a changing seasonality.

The LR-CESM configuration diagnoses the bolus eddyinduced advection (from the GM parameterization) and the submesoscale advection (from the biharmonic diffusion). Figure B2 compares the diagnosed GM (blue) and submesoscale (orange) freshwater transport terms to the eddy term (Eq. B14; green). The GM parameterization term is generally significantly smaller than the term arising from the $\mathrm{Eu}-$ lerian eddy-mean decomposition (for both monthly and annual cutoff timescales) but can be comparable in size (e.g., at the Equator or the NA-STG). The submesoscale term, on the other hand, is negligible compared to the other two terms. 
HR-CESM
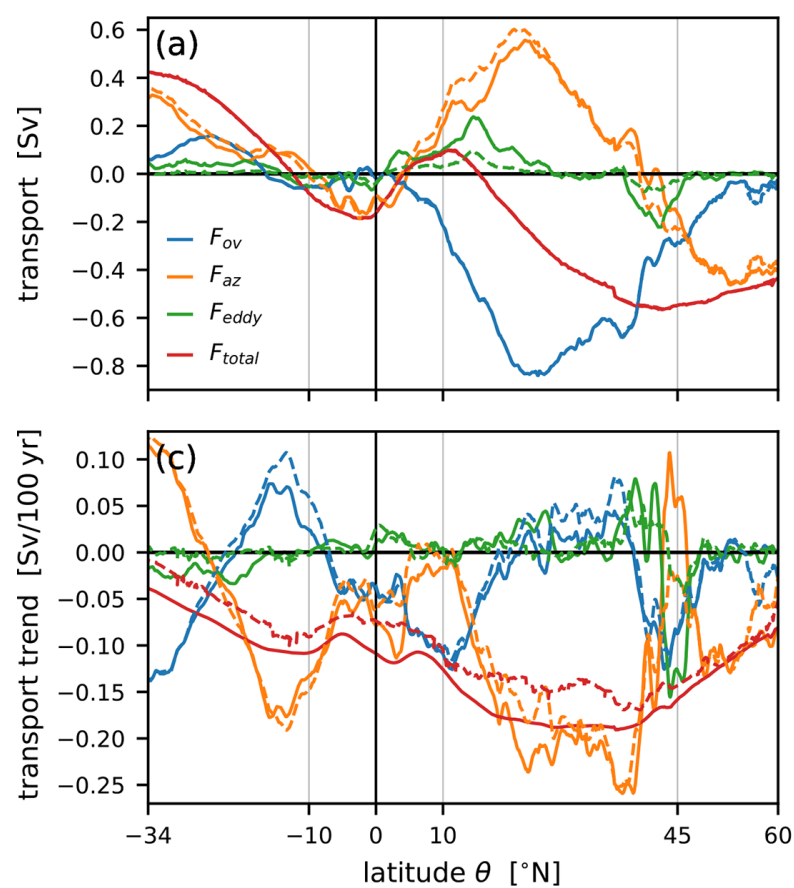

LR-CESM
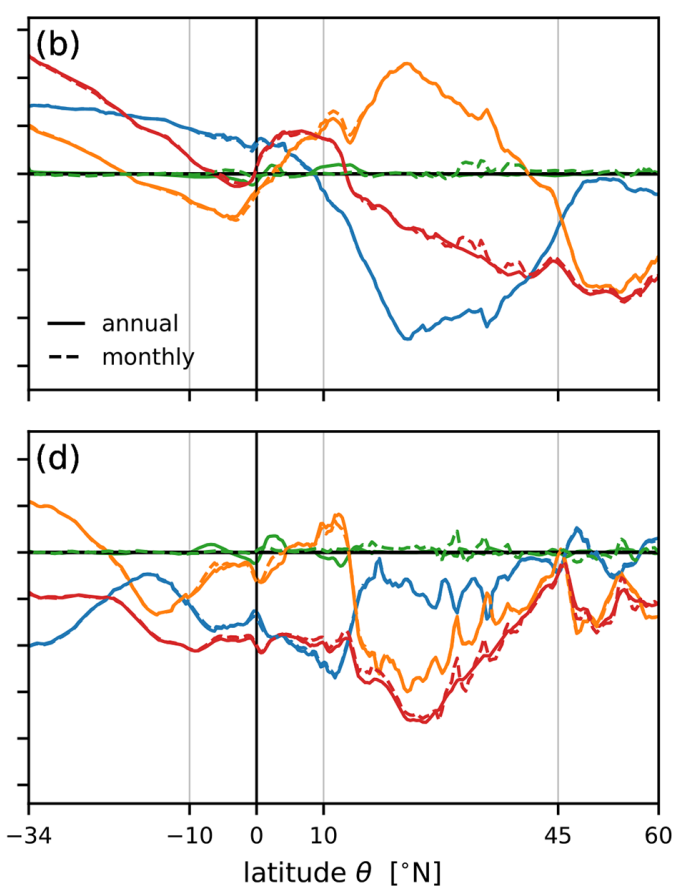

Figure B1. Freshwater transport terms calculated from annually (solid lines; as in Figs. 7, 9, and 10) vs. monthly (dashed) averaged model output. The difference is the effect of seasonality.

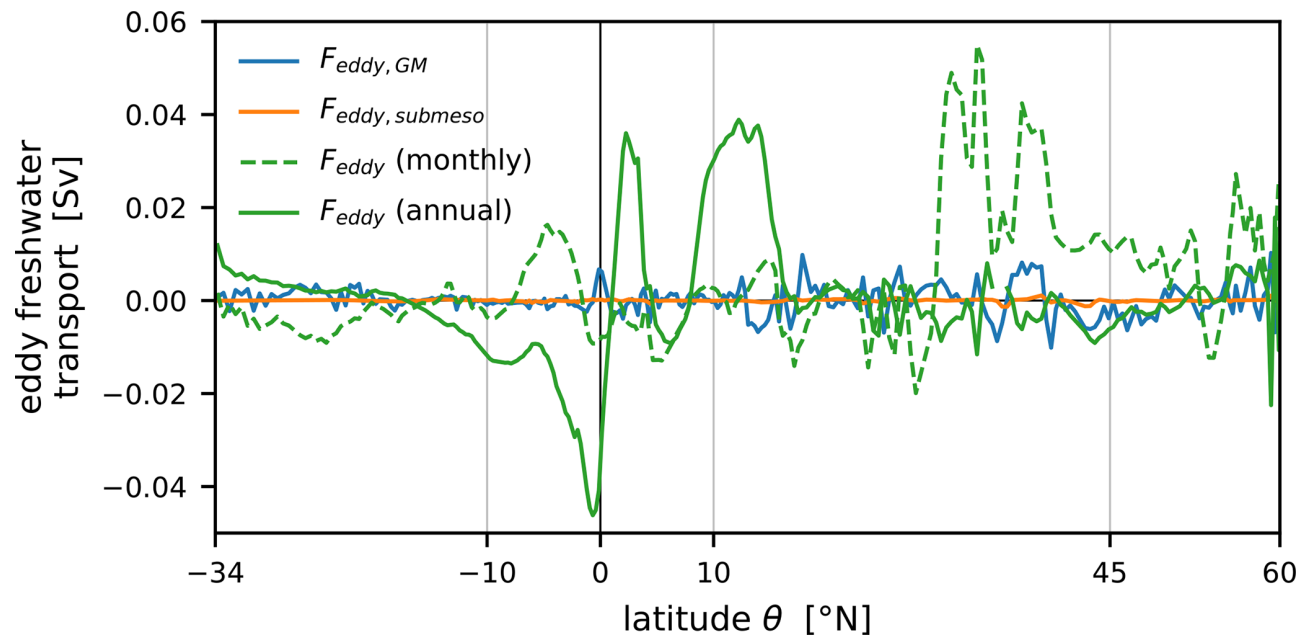

Figure B2. Freshwater transport terms calculated from the eddy salt advection terms diagnosed by the LR-CESM model compared to the monthly and annual $F_{\text {eddy }}$ term (green) which are shown in Figs. $7 \mathrm{~b}$ and B1. The model diagnoses salt advection by the GM parameterization (blue) and the submesoscale mixing parameterization (orange). 
Code and data availability. The analysis scripts are available at https://doi.org/10.5281/zenodo.4537845 (Jüling, 2021), while the model output is stored at SURFsara and available upon request to the corresponding author.

Author contributions. AJ, ASvdH, DC, and HAD conceived the presented ideas in this study. AJ performed the analysis and wrote the manuscript. XZ carried out some initial analysis. ASvdH, DC, and HAD contributed to writing the paper.

Competing interests. The authors declare that they have no conflict of interest.

Acknowledgements. The computations were performed on the Cartesius high-performance computer at SURFsara in Amsterdam. Use of the Cartesius computing facilities was sponsored by the Netherlands Science Foundation (NWO; project no. 17239). The authors are grateful to Michael Kliphuis (IMAU) for carrying out the CESM simulations.

Financial support. This work was carried out in the framework of the Netherlands Earth System Science Centre (NESSC) program, which was financially supported by the Ministry of Education, Culture and Science (OCW; grant no. 024.002.001).

Review statement. This paper was edited by Markus Meier and reviewed by two anonymous referees.

\section{References}

Behrens, E., Biastoch, A., and Böning, C. W.: Spurious AMOC trends in global ocean sea-ice models related to subarctic freshwater forcing, Ocean Model., 69, 39-49, https://doi.org/10.1016/j.ocemod.2013.05.004, 2013.

Brunnabend, S. E. and Dijkstra, H. A.: Asymmetric response of the Atlantic Meridional Ocean Circulation to freshwater anomalies in a strongly-eddying global ocean model, Tellus A, 69, 1-15, https://doi.org/10.1080/16000870.2017.1299283, 2017.

Bryden, H. L., King, B. A., and McCarthy, G. D.: South Atlantic overturning circulation at 24S, J. Mar. Res., 69, 39-56, https://doi.org/10.1357/002224011798147633, 2011.

Caesar, L., Rahmstorf, S., Robinson, A., Feulner, G., and Saba, V.: Observed fingerprint of a weakening Atlantic Ocean overturning circulation, Nature, 556, 191-196, https://doi.org/10.1038/s41586-018-0006-5, 2018.

Cheng, W., Chiang, J. C., and Zhang, D.: Atlantic meridional overturning circulation (AMOC) in CMIP5 Models: RCP and historical simulations, J. Climate, 26, 7187-7197, https://doi.org/10.1175/JCLI-D-12-00496.1, 2013.

Cimatoribus, A. A., Drijfhout, S. S., den Toom, M., and Dijkstra, H. A.: Sensitivity of the Atlantic meridional overturning circu- lation to South Atlantic freshwater anomalies, Clim. Dyn., 39, 2291-2306, https://doi.org/10.1007/s00382-012-1292-5, 2012.

Davies-Barnard, T., Valdes, P. J., Singarayer, J. S., Pacifico, F. M., and Jones, C. D.: Full effects of land use change in the representative concentration pathways, Environ. Res. Lett., 9, 114014, https://doi.org/10.1088/1748-9326/9/11/114014, 2014.

de Vries, P.: The Atlantic freshwater budget as a diagnostic for the existence of a stable shut down of the meridional overturning circulation, Geophys. Res. Lett., 32, L09606, https://doi.org/10.1029/2004GL021450, 2005.

Dee, D. P., Uppala, S. M., Simmons, A. J., Berrisford, P., Poli, P., Kobayashi, S., Andrae, U., Balmaseda, M. A., Balsamo, G., Bauer, P., Bechtold, P., Beljaars, A. C. M., van de Berg, L., Bidlot, J., Bormann, N., Delsol, C., Dragani, R., Fuentes, M., Geer, A. J., Haimberger, L., Healy, S. B., Hersbach, H., Hólm, E. V., Isaksen, L., Kållberg, P., Köhler, M., Matricardi, M., McNally, A. P., Monge-Sanz, B. M., Morcrette, J.-J., Park, B.-K., Peubey, C., de Rosnay, P., Tavolato, C., Thépaut, J.-N., and Vitart, F.: The ERA-Interim reanalysis: configuration and performance of the data assimilation system, Q. J. Roy. Meteor. Soc., 137, 553-597, https://doi.org/10.1002/qj.828, 2011.

den Toom, M., Dijkstra, H. A., Weijer, W., Hecht, M. W., Maltrud, M. E., and van Sebille, E.: Response of a Strongly Eddying Global Ocean to North Atlantic Freshwater Perturbations, J. Phys. Oceanogr., 44, 464-481, https://doi.org/10.1175/JPO-D12-0155.1, 2014.

Deshayes, J., Tréguier, A.-M., Barnier, B., Lecointre, A., Sommer, J. L., Molines, J.-M., Penduff, T., Bourdallé-Badie, R., Drillet, Y., Garric, G., Benshila, R., Madec, G., Biastoch, A., Böning, C. W., Scheinert, M., Coward, A. C., and Hirschi, J. J.: Oceanic hindcast simulations at high resolution suggest that the Atlantic MOC is bistable, Geophys. Res. Lett., 40, 3069-3073, https://doi.org/10.1002/grl.50534, 2013.

Dijkstra, H. A.: Characterization of the multiple equilibria regime in a global ocean model, Tellus A, 59, 695-705, https://doi.org/10.1111/j.1600-0870.2007.00267.x, 2007.

Drijfhout, S., van Oldenborgh, G. J., and Cimatoribus, A.: Is a decline of AMOC causing the warming hole above the North Atlantic in observed and modeled warming patterns?, J. Climate, 25, 8373-8379, https://doi.org/10.1175/JCLI-D-12$00490.1,2012$.

Drijfhout, S. S., Weber, S. L., and van der Swaluw, E.: The stability of the MOC as diagnosed from model projections for preindustrial, present and future climates, Clim. Dyn., 37, 15751586, https://doi.org/10.1007/s00382-010-0930-z, 2011.

Frajka-Williams, E., Ansorge, I. J., Baehr, J., Bryden, H. L., Chidichimo, M. P., Cunningham, S. A., Danabasoglu, G., Dong, S., Donohue, K. A., Elipot, S., Heimbach, P., Holliday, N. P., Hummels, R., Jackson, L. C., Karstensen, J., Lankhorst, M., Le Bras, I. A., Susan Lozier, M., McDonagh, E. L., Meinen, C. S., Mercier, H., Moat, B. I., Perez, R. C., Piecuch, C. G., Rhein, M., Srokosz, M. A., Trenberth, K. E., Bacon, S., Forget, G., Goni, G., Kieke, D., Koelling, J., Lamont, T., McCarthy, G. D., Mertens, C., Send, U., Smeed, D. A., Speich, S., van den Berg, M., Volkov, D., and Wilson, C.: Atlantic meridional overturning circulation: Observed transport and variability, Front. Mar. Sci., 6, 1-18, https://doi.org/10.3389/fmars.2019.00260, 2019. 
Gent, P. R.: A commentary on the Atlantic meridional overturning circulation stability in climate models, Ocean Model., 122, 5766, https://doi.org/10.1016/j.ocemod.2017.12.006, 2018.

Gent, P. R. and McWilliams, J. C.: Isopycnal Mixing in Ocean Circulation Models, J. Phys. Oceanogr., 20, 150-155, 1990.

Good, S. A., Martin, M. J., and Rayner, N. A.: EN4: Quality controlled ocean temperature and salinity profiles and monthly objective analyses with uncertainty estimates, J. Geophys. Res.-Oceans, 118, 6704-6716, https://doi.org/10.1002/2013JC009067, 2013.

Gregory, J. M., Dixon, K. W., Stouffer, R. J., Weaver, A. J., Driesschaert, E., Eby, M., Fichefet, T., Hasumi, H., Hu, A., Jungclaus, J. H., Kamenkovich, I. V., Levermann, A., Montoya, M., Murakami, S., Nawrath, S., Oka, A., Sokolov, A. P., and Thorpe, R. B.: A model intercomparison of changes in the Atlantic thermohaline circulation in response to increasing atmospheric $\mathrm{CO}_{2}$ concentration, Geophys. Res. Lett., 32, 1-5, https://doi.org/10.1029/2005GL023209, 2005.

Hallberg, R.: Using a resolution function to regulate parameterizations of oceanic mesoscale eddy effects, Ocean Model., 72, 92103, https://doi.org/10.1016/j.ocemod.2013.08.007, 2013.

Hawkins, E., Smith, R. S., Allison, L. C., Gregory, J. M., Woollings, T. J., Pohlmann, H., and de Cuevas, B.: Bistability of the Atlantic overturning circulation in a global climate model and links to ocean freshwater transport, Geophys. Res. Lett., 38, L10605, https://doi.org/10.1029/2011GL047208, 2011.

Held, I. M. and Soden, B. J.: Robust Responses of the Hydrological Cycle to Global Warming, J. Climate, 19, 5686-5699, https://doi.org/10.1175/JCLI3990.1, 2006.

Hirschi, J. J. J., Barnier, B., Böning, C., Biastoch, A., Blaker, A. T., Coward, A., Danilov, S., Drijfhout, S., Getzlaff, K., Griffies, S. M., Hasumi, H., Hewitt, H., Iovino, D., Kawasaki, T., Kiss, A. E., Koldunov, N., Marzocchi, A., Mecking, J. V., Moat, B., Molines, J. M., Myers, P. G., Penduff, T., Roberts, M., Treguier, A. M., Sein, D. V., Sidorenko, D., Small, J., Spence, P., Thompson, L. A., Weijer, W., and Xu, X.: The Atlantic meridional overturning circulation in high resolution models, J. Geophys. Res.Oceans, 53, 1689-1699, https://doi.org/10.1029/2019JC015522, 2020.

Huisman, S. E., den Toom, M., Dijkstra, H. A., and Drijfhout, S.: An Indicator of the Multiple Equilibria Regime of the Atlantic Meridional Overturning Circulation, J. Phys. Oceanogr., 40, 551-567, https://doi.org/10.1175/2009JPO4215.1, 2010.

Hurrell, J. W., Holland, M. M., Gent, P. R., Ghan, S., Kay, J. E., Kushner, P. J., Lamarque, J.-F., Large, W. G., Lawrence, D., Lindsay, K., Lipscomb, W. H., Long, M. C., Mahowald, N., Marsh, D. R., Neale, R. B., Rasch, P., Vavrus, S., Vertenstein, M., Bader, D., Collins, W. D., Hack, J. J., Kiehl, J., and Marshall, S.: The Community Earth System Model: A Framework for Collaborative Research, B. Am. Meteorol. Soc., 94, 13391360, https://doi.org/10.1175/BAMS-D-12-00121.1, 2013.

Jackson, L. C., Roberts, M. J., Hewitt, H. T., Iovino, D., Koenigk, T., Meccia, V. L., Roberts, C. D., Ruprich-Robert, Y., and Wood, R. A.: Impact of ocean resolution and mean state on the rate of AMOC weakening, Clim. Dyn., 55, 1711-1732, https://doi.org/10.1007/s00382-020-05345-9, 2020.

Johns, W. E., Baringer, M. O., Beal, L. M., Cunningham, S. A., Kanzow, T., Bryden, H. L., Hirschi, J. J. M., Marotzke, J., Meinen, C. S., Shaw, B., and Curry, R.: Continuous, Array-Based Esti- mates of Atlantic Ocean Heat Transport at 26.5N, J. Climate, 24, 2429-2449, https://doi.org/10.1175/2010JCLI3997.1, 2011.

Jüling, A.: Code and documentation to reproduce results of Ocean Science paper "The Atlantic's freshwater budget under climate change in the Community Earth System Model with strongly eddying oceans", Zenodo, https://doi.org/10.5281/zenodo.4537845, last access: 30 April 2021.

Jüling, A., von der Heydt, A., and Dijkstra, H. A.: Effects of strongly eddying oceans on multidecadal climate variability in the Community Earth System Model, Ocean Sci. Discuss. [preprint], https://doi.org/10.5194/os-2020-85, in review, 2020.

Kirtman, B. P., Bitz, C., Bryan, F., Collins, W., Dennis, J., Hearn, N., Kinter, J. L., Loft, R., Rousset, C., Siqueira, L., Stan, C., Tomas, R., and Vertenstein, M.: Impact of ocean model resolution on CCSM climate simulations, Clim. Dyn., 39, 1303-1328, https://doi.org/10.1007/s00382-012-1500-3, 2012.

Lenton, T. M., Held, H., Kriegler, E., Hall, J. W., Lucht, W., Rahmstorf, S., and Schellnhuber, H. J.: Tipping elements in the Earth's climate system, P. Natl. Acad. Sci., 105, 1786-1793, https://doi.org/10.1073/pnas.0705414105, 2008.

Liu, W., Liu, Z., and Brady, E. C.: Why is the AMOC monostable in coupled general circulation models?, J. Climate, 27, 2427-2443, https://doi.org/10.1175/JCLI-D-13-00264.1, 2014.

Liu, W., Xie, S.-P., Liu, Z., and Zhu, J.: Overlooked possibility of a collapsed Atlantic Meridional Overturning Circulation in warming climate, Sci. Adv., 3, e1601666, https://doi.org/10.1126/sciadv.1601666, 2017.

Lynch-Stieglitz, J.: The Atlantic Meridional Overturning Circulation and Abrupt Climate Change, Annu. Rev. Mar. Sci., 9, 83-104, https://doi.org/10.1146/annurev-marine-010816060415, 2017.

McDonagh, E. L., Heywood, K. J., and Meredith, M. P.: On the structure, paths, and fluxes associated with Agulhas rings, J. Geophys. Res.-Oceans, 104, 21007-21020, https://doi.org/10.1029/1998JC900131, 1999.

Mecking, J., Drijfhout, S., Jackson, L., and Andrews, M.: The effect of model bias on Atlantic freshwater transport and implications for AMOC bi-stability, Tellus A, 69, 1299910, https://doi.org/10.1080/16000870.2017.1299910, 2017.

Mecking, J. V., Drijfhout, S. S., Jackson, L. C., and Graham, T.: Stable AMOC off state in an eddy-permitting coupled climate model, Clim. Dyn., 47, 2455-2470, https://doi.org/10.1007/s00382-016-2975-0, 2016.

Meehl, G. A., Washington, W. M., Arblaster, J. M., Hu, A., Teng, H., Kay, J. E., Gettelman, A., Lawrence, D. M., Sanderson, B. M., and Strand, W. G.: Climate change projections in CESM1(CAM5) compared to CCSM4, J. Clim., 26, 6287-6308, https://doi.org/10.1175/JCLI-D-12-00572.1, 2013.

Menary, M. B. and Wood, R. A.: An anatomy of the projected North Atlantic warming hole in CMIP5 models, Clim. Dyn., 50, 30633080, https://doi.org/10.1007/s00382-017-3793-8, 2018.

Moat, B. I., Frajka-Williams, E., Smeed, D., Rayner, D., SanchezFranks, A., Johns, W. E., Baringer, M. O., Volkov, D. L., and Collins, J.: Atlantic meridional overturning circulation observed by the RAPID-MOCHA-WBTS (RAPID-Meridional Overturning Circulation and Heat ux Array-Western Boundary Time Series) array at $26 \mathrm{~N}$ from 2004 to 2018 (v2018.2), [Dataset], British Oceanographic Data Centre, National Oceanogra- 
phy Centre, NERC, UK, https://doi.org/10.5285/aa57e879-4cca28b6-e053-6c86abc02de5, 2020.

Moreton, S. M., Ferreira, D., Roberts, M. J., and Hewitt, H. T.: Evaluating surface eddy properties in coupled climate simulations with 'eddy-present' and 'eddyrich' ocean resolution, Ocean Model., 147, 101567, https://doi.org/10.1016/j.ocemod.2020.101567, 2020.

Palter, J. B.: The Role of the Gulf Stream in European Climate, Annu. Rev. Mar. Sci., 7, 113-137, https://doi.org/10.1146/annurev-marine-010814-015656, 2015.

Peltier, W. R. and Vettoretti, G.: Dansgaard-Oeschger oscillations predicted in a comprehensive model of glacial climate: A "kicked" salt oscillator in the Atlantic, Geophys. Res. Lett., 41, 7306-7313, https://doi.org/10.1002/2014GL061413, 2014.

Rahmstorf, S.: On the freshwater forcing and transport of the Atlantic thermohaline circulation, Clim. Dyn., 12, 799-811, https://doi.org/10.1007/s003820050144, 1996.

Rahmstorf, S., Crucifix, M., Ganopolski, A., Goosse, H., Kamenkovich, I., Knutti, R., Lohmann, G., Marsh, R., Mysak, L. A., Wang, Z., and Weaver, A. J.: Thermohaline circulation hysteresis: A model intercomparison, Geophys. Res. Lett., 32, L23605, https://doi.org/10.1029/2005GL023655, 2005.

Rayner, N. A., Parker, D. E., Horton, E. B., Folland, C. K., Alexander, L. V., and Rowell, D. P.: Global analyses of sea surface temperature, sea ice, and night marine air temperature since the late nineteenth century, J. Geophys. Res., 108, 4407, https://doi.org/10.1029/2002JD002670, 2003.

Sánchez-Román, A., Sannino, G., García-Lafuente, J., Carillo, A., and Criado-Aldeanueva, F.: Transport estimates at the western section of the Strait of Gibraltar: A combined experimental and numerical modeling study, J. Geophys. Res.-Oceans, 114, 1-15, https://doi.org/10.1029/2008JC005023, 2009.

Schauer, U. and Losch, M.: "Freshwater" in the Ocean is Not a Useful Parameter in Climate Research, J. Phys. Oceanogr., 49, 23092321, https://doi.org/10.1175/JPO-D-19-0102.1, 2019.

Skliris, N., Marsh, R., Mecking, J. V., and Zika, J. D.: Changing water cycle and freshwater transports in the Atlantic Ocean in observations and CMIP5 models, Clim. Dyn., 19, 2017-8976, https://doi.org/10.1007/s00382-020-05261-y, 2020.

Small, R. J., Bacmeister, J., Bailey, D., Baker, A., Bishop, S., Bryan, F., Caron, J., Dennis, J., Gent, P., Hsu, H., Jochum, M., Lawrence, D., Muñoz, E., DiNezio, P., Scheitlin, T., Tomas, R., Tribbia, J., Tseng, Y., and Vertenstein, M.: A new synoptic scale resolving global climate simulation using the Community Earth System Model, J. Adv. Model. Earth Sy., 6, 1065-1094, https://doi.org/10.1002/2014MS000363, 2014.

Smeed, D. A., Josey, S. A., Beaulieu, C., Johns, W. E., Moat, B. I., Frajka-Williams, E., Rayner, D., Meinen, C. S., Baringer, M. O., Bryden, H. L., and McCarthy, G. D.: The North Atlantic Ocean Is in a State of Reduced Overturning, Geophys. Res. Lett., 45, 1527-1533, https://doi.org/10.1002/2017GL076350, 2018.

Smith, R., Jones, P., Briegleb, B., Bryan, F., Danabasoglu, G., Dennis, J., Dukowicz, J., Eden, C., Fox-Kemper, B., Gent, P., Hecht, M., Jayne, S., Jochum, M., Large, W., Lindsay, K., Maltrud, M., Norton, N., Peacock, S., Vertenstein, M., and Yeager, S.: The Parallel Ocean Program (POP) Reference Manual, LAUR-01853, 141, 1-140, 2010.

Srokosz, M., Baringer, M., Bryden, H., Cunningham, S., Delworth, T., Lozier, S., Marotzke, J., and Sutton, R.: Past,
Present, and Future Changes in the Atlantic Meridional Overturning Circulation, B. Am. Meteorol. Soc., 93, 1663-1676, https://doi.org/10.1175/bams-d-11-00151.1, 2012.

Stocker, T. F., Qin, D., Plattner, G.-K., Tignor, M., Allen, S. K., Boschung, J., Nauels, A., Xia, Y., And, V. B., and Midgley, P. M.: IPCC, 2013: Climate Change 2013: The Physical Science Basis. Contribution of Working Group I to the Fifth Assessment Report of the Intergovernmental Panel on Climate Change, Cambridge University Press, Cambridge, https://doi.org/10.1017/CBO9781107415324, 2013.

Stommel, H.: Thermohaline Convection with Two Stable Regimes of Flow, Tellus A, 13, 224-230, https://doi.org/10.3402/tellusa.v13i2.9491, 1961.

Toom, M. D., Dijkstra, H. A., Cimatoribus, A. A., and Drijfhout, S. S.: Effect of atmospheric feedbacks on the stability of the Atlantic meridional overturning circulation, J. Climate, 25, 40814096, https://doi.org/10.1175/JCLI-D-11-00467.1, 2012.

Treguier, A. M., Deshayes, J., Lique, C., Dussin, R., and Molines, J. M.: Eddy contributions to the meridional transport of salt in the North Atlantic, J. Geophys. Res.-Oceans, 117, 1-19, https://doi.org/10.1029/2012JC007927, 2012.

Treguier, A. M., Deshayes, J., Le Sommer, J., Lique, C., Madec, G., Penduff, T., Molines, J.-M., Barnier, B., Bourdalle-Badie, R., and Talandier, C.: Meridional transport of salt in the global ocean from an eddy-resolving model, Ocean Sci., 10, 243-255, https://doi.org/10.5194/os-10-243-2014, 2014.

Trenberth, K. E., Fasullo, J. T., and Mackaro, J.: Atmospheric moisture transports from ocean to land and global energy flows in reanalyses, J. Climate, 24, 4907-4924, https://doi.org/10.1175/2011JCLI4171.1, 2011.

van Vuuren, D. P., Edmonds, J., Kainuma, M., Riahi, K., Thomson, A., Hibbard, K., Hurtt, G. C., Kram, T., Krey, V., Lamarque, J. F., Masui, T., Meinshausen, M., Nakicenovic, N., Smith, S. J., and Rose, S. K.: The representative concentration pathways: An overview, Clim. Change, 109, 5-31, https://doi.org/10.1007/s10584-011-0148-z, 2011.

van Westen, R. M. and Dijkstra, H. A.: Southern Ocean Origin of Multidecadal Variability in the North Brazil Current, Geophys. Res. Lett., 44, 10510-10548, https://doi.org/10.1002/2017GL074815, 2017.

Weaver, A. J., Sedláček, J., Eby, M., Alexander, K., Crespin, E., Fichefet, T., Philippon-Berthier, G., Joos, F., Kawamiy, M., Matsumoto, K., Steinacher, M., Tachiiri, K., Tokos, K., Yoshimori, M., and Zickfeld, K.: Stability of the Atlantic meridional overturning circulation: A model intercomparison, Geophys. Res. Lett., 39, 1-8, https://doi.org/10.1029/2012GL053763, 2012.

Weijer, W., Maltrud, M. E., Hecht, M. W., Dijkstra, H. A., and Kliphuis, M. A.: Response of the Atlantic Ocean circulation to Greenland Ice Sheet melting in a stronglyeddying ocean model, Geophys. Res. Lett., 39, L09606, https://doi.org/10.1029/2012GL051611, 2012.

Weijer, W., Cheng, W., Drijfhout, S. S., Fedorov, A. V., Hu, A., Jackson, L. C., Liu, W., McDonagh, E. L., Mecking, J. V., and Zhang, J.: Stability of the Atlantic Meridional Overturning Circulation: A Review and Synthesis, J. Geophys. Res.-Oceans, 124, 5336-5375, https://doi.org/10.1029/2019JC015083, 2019.

Winton, M., Anderson, W. G., Delworth, T. L., Griffies, S. M., Hurlin, W. J., and Rosati, A.: Has coarse ocean resolution biased 
simulations of transient climate sensitivity?, Geophys. Res. Lett., 41, 8522-8529, https://doi.org/10.1002/2014GL061523, 2014.

Woodgate, R. A. and Aagaard, K.: Revising the Bering Strait freshwater flux into the Arctic Ocean, Geophys. Res. Lett., 32, 1-4, https://doi.org/10.1029/2004GL021747, 2005.

Yang, H., Lohmann, G., Krebs-Kanzow, U., Ionita, M., Shi, X., Sidorenko, D., Gong, X., Chen, X., and Gowan, E. J.: Poleward Shift of the Major Ocean Gyres Detected in a Warming Climate, Geophys. Res. Lett., 47, e2019GL085868, https://doi.org/10.1029/2019GL085868, 2020.

Yin, J. and Stouffer, R. J.: Comparison of the stability of the Atlantic thermohaline circulation in two coupled atmosphere Ocean general circulation models, J. Climate, 20, 4293-4315, https://doi.org/10.1175/JCLI4256.1, 2007.
Ypma, S., Brüggemann, N., Georgiou, S., Spence, P., Dijkstra, H., Pietrzak, J., and Katsman, C.: Pathways and watermass transformation of Atlantic Water entering the Nordic Seas through Denmark Strait in two high resolution ocean models, Deep-Sea Res. Pt. I, 145, 59-72, https://doi.org/10.1016/j.dsr.2019.02.002, 2019.

Zlotnicki, V., Qu, Z., and Willis, J.: MEaSUREs Gridded Sea Surface Height Anomalies Version 1812, NASA Physical Oceanography DAAC, [Dataset], https://podaac.jpl.nasa.gov/dataset/SEA_SURFACE_HEIGHT_ ALT_GRIDS_L4_2SATS_5DAY_6THDEG_V_JPL1812 (last access: 7 November 2020), 2019. 